\title{
Relationships between fertility and postpartum changes in body condition and body weight in lactating dairy cows
}

\author{
P. D. Carvalho, ${ }^{*}$ A. H. Souza, ${ }^{* 1}$ M. C. Amundson, ${ }^{*}$ K. S. Hackbart, ${ }^{*}$ M. J. Fuenzalida, ${ }^{*}$ M. M. Herlihy, \\ H. Ayres, ${ }^{*}$ A. R. Dresch, ${ }^{*}$ L. M. Vieira, ${ }^{*}$ J. N. Guenther, ${ }^{*}$ R. R. Grummer,† P. M. Fricke, ${ }^{*}$ \\ R. D. Shaver, ${ }^{*}$ and M. C. Wiltbank ${ }^{\star 2}$ \\ *Department of Dairy Science, University of Wisconsin-Madison, Madison 53706 \\ †Balchem Corporation, New Hampton, NY 10958
}

\begin{abstract}
The relationship between energy status and fertility in dairy cattle was retrospectively analyzed by comparing fertility with body condition score (BCS) near artificial insemination (AI; experiment 1), early postpartum changes in BCS (experiment 2), and postpartum changes in body weight (BW; experiment 3 ). To reduce the effect of cyclicity status, all cows were synchronized with Double-Ovsynch protocol before timed AI. In experiment $1, \mathrm{BCS}$ of lactating dairy cows $(\mathrm{n}=$ $1,103)$ was evaluated near AI. Most cows (93\%) were cycling at initiation of the breeding Ovsynch protocol (first GnRH injection). A lower percentage pregnant to $\mathrm{AI}(\mathrm{P} / \mathrm{AI})$ was found in cows with lower $(\leq 2.50)$ versus higher $(\geq 2.75)$ BCS (40.4 vs. $49.2 \%$ ). In experiment 2 , lactating dairy cows on 2 commercial dairies $(\mathrm{n}=$ 1,887 ) were divided by BCS change from calving until the third week postpartum. Overall, P/AI at 70-d pregnancy diagnosis differed dramatically by BCS change and was least for cows that lost BCS, intermediate for cows that maintained BCS, and greatest for cows that gained BCS [22.8\% (180/789), 36.0\% (243/675), and $78.3 \%(331 / 423)$, respectively]. Surprisingly, a difference existed between farms with BCS change dramatically affecting $\mathrm{P} / \mathrm{AI}$ on one farm and no effect on the other farm. In experiment 3, lactating dairy cows $(\mathrm{n}=$ 71) had BW measured weekly from the first to ninth week postpartum and then had superovulation induced using a modified Double-Ovsynch protocol. Cows were divided into quartiles $(\mathrm{Q})$ by percentage of $\mathrm{BW}$ change (Q1 = least change; $\mathrm{Q} 4=$ most change $)$ from calving until the third week postpartum. No effect was detected of quartile on number of ovulations, total embryos collected, or percentage of oocytes that were fertilized; however, the percentage of fertilized oocytes that were
\end{abstract}

\footnotetext{
Received December 7, 2013.

Accepted March 3, 2014.

${ }^{1}$ Current address: University of California Cooperative Extension, Tulare, CA 93274.

${ }^{2}$ Corresponding author: wiltbank@wisc.edu
}

transferable embryos was greater for cows in Q1, Q2, and Q3 than Q4 (83.8, 75.2, 82.6, and 53.2\%, respectively). In addition, percentage of degenerated embryos was least for cows in Q1, Q2, and Q3 and greatest for Q4 (9.6, 14.5, 12.6, and $35.2 \%$ respectively). In conclusion, for cows synchronized with a Double-Ovsynch protocol, an effect of low BCS $(\leq 2.50)$ near AI on fertility was detected, but change in BCS during the first 3 wk postpartum had a more profound effect on $\mathrm{P} / \mathrm{AI}$ to first timed AI. This effect could be partially explained by the reduction in embryo quality and increase in degenerate embryos by d 7 after $\mathrm{AI}$ in cows that lost more BW from the first to third week postpartum.

Key words: body condition score loss, body weight loss, embryo quality, fertility

\section{INTRODUCTION}

The transition period, defined as the period from 3 wk before to 3 wk after calving, represents a challenge for dairy cows as milk production and DMI increase dramatically (Bell, 1995; Grummer, 1995; Herdt, 2000). In some cows, a lack of optimal synchronization of these 2 processes can result in negative energy balance (NEB; Herdt, 2000; Grummer, 2008), fat mobilization from adipose tissue (Herdt, 2000; Weber et al., 2013), and losses in BCS and BW (Ferguson, 1996; Grummer and Rastani, 2003). The association of energy status during the transition period and reproductive efficiency in dairy cows has been demonstrated in multiple studies. For example, a retrospective analysis of 7 studies of prepartum nutrition found that feeding a high-energy diet during the close-up period resulted in increased BCS loss postpartum and increased time to pregnancy (Cardoso et al., 2013). In addition, 2 studies found that increases in NEFA concentrations during the transition period were predictive of reduced risk of pregnancy by $70 \mathrm{~d}$ after the voluntary waiting period in evaluations of $>2,000$ lactating dairy cows (Ospina et al., 2010b) or reduced 21-d pregnancy rate in herd-level evaluations of 60 freestall herds (Ospina et al., 2010a). Recently, 
a study of 156 lactating dairy cows (Garverick et al., 2013) reported that the probability of pregnancy at first timed AI (TAI) was decreased as serum NEFA concentrations on d-3 postpartum increased. Other studies also indicate a negative relationship between postpartum NEFA or loss of BCS and fertility (LópezGatius et al., 2003; Chapinal et al., 2012b). In contrast, no effect of increased NEFA or BHBA concentrations during the transition period was found in a recent large $(\mathrm{n}=2,365)$, multi-region study (Chapinal et al., 2012a). Unfortunately, none of those studies provided detailed information on reproductive management protocols, except for Garverick et al. (2013). Thus, further studies on the effects of early postpartum energy balance on reproductive performance, particularly in herds using systematic reproductive synchronization protocols, could provide valuable information on biological mechanisms regulating reproductive efficiency as well as practical strategies for managing reproduction in dairy herds.

Multiple potential mechanisms exist whereby energy status during the postpartum period could reduce fertility in dairy cows. Negative energy balance decreases dominant follicle growth and estradiol production, possibly because of decreases in circulating insulin, IGF-1, and LH pulses (Canfield and Butler, 1990; Butler, 2003, 2005). A longer time from calving until energy balance nadir has been associated with an increased interval to first postpartum ovulation (Canfield and Butler, 1990; Zurek et al., 1995; Gümen et al., 2005). In addition, the magnitude of BCS loss after calving can increase the percentage of cows that are not cycling at the end of the voluntary waiting period (Gümen et al., 2003, Santos et al., 2004a, 2009; Lopez et al., 2005). Thus, early postpartum NEB may decrease reproductive efficiency by increasing the percentage of anovular cows. Indeed, anovular cows have lower reproductive efficiency in programs using detection of estrus or TAI protocols (Gümen et al., 2003; Santos et al., 2009). Furthermore, cows that begin TAI programs in a low-progesterone (P4) environment have reduced fertility, independent of cyclicity status (Denicol et al., 2012; Giordano et al., 2012b; Lopes et al., 2013). In addition, cows with lower BCS near the time of AI have decreased fertility (Moreira et al., 2000; Souza et al., 2008; Santos et al., 2009) and this may be related to increased anovulation as BCS decreases. Of particular importance to the current study, excessive BCS loss between parturition and first insemination is associated with poor reproductive performance (López-Gatius et al., 2003; Santos et al., 2009). A classical hypothesis was introduced by Britt (1992), who postulated that energy status during the early postpartum period could alter follicular/oocyte quality, resulting in negative effects on subsequent fertility in lactating dairy cows. However, definitive evidence for this hypothesis as well as definition of the cellular mechanisms and reproductive targets of early postpartum NEB (fertilization or early embryo development) has not yet been delineated.

In this study, we conducted a retrospective analysis of previous studies in which we had indicators of energy balance during the postpartum period (BCS, BCS changes, and BW losses) and fertility measurements at first postpartum AI. To minimize the potential confounding effects of cyclicity status at initiation of the Ovsynch56 protocol (Denicol et al., 2012; Giordano et al., 2012a,b, 2013), we chose to evaluate only cows that had been treated with a Double-Ovsynch protocol, which induces cyclicity in most cows before beginning the breeding Ovsynch protocol (Herlihy et al., 2012; Ayres et al., 2013). Our specific objectives were to (1) evaluate the association between BCS near TAI on fertility at first AI, (2) evaluate the association between BCS change early postpartum on fertility of lactating dairy cows at first AI, and (3) evaluate the effect of postpartum BW change on circulating NEFA concentrations and embryo production in high-producing dairy cows that were superovulated at first AI. Our hypotheses were (1) cows with low BCS near AI will have decreased fertility at first TAI, (2) cows with greater BCS loss early postpartum will have decreased fertility at first TAI compared with cows with lesser BCS loss, and (3) cows with increased postpartum BW loss will have greater circulating NEFA concentrations and poorer embryo quality.

\section{MATERIALS AND METHODS}

All procedures were approved by the Animal Care and Use Committee for the College of Agricultural and Life Sciences of the University of Wisconsin-Madison.

\section{Experiment 1}

Animals, Housing, and AI. This experiment was conducted on 3 commercial dairy farms and 1 research farm in south-central Wisconsin. Lactating dairy cows ( $\mathrm{n}=1,103 ; 465$ primiparous and 638 multiparous) were housed in freestall facilities bedded with sand and equipped with self-locking head gates at the feed line, and had ad libitum access to fresh feed and water. Cows were milked 3 times daily on the commercial farms, whereas cows were milked twice daily at the research farm. Cows were fed TMR diets using corn and alfalfa silage as forage and corn- and soybean-meal based concentrates and supplemented with minerals and vitamins. On all farms, TMR diets were balanced by a professional nutritionist using the NRC (2001) 
nutritional requirements for lactating dairy cows. All cows in the commercial farms received bST every 11 $\mathrm{d}$ beginning at $63 \pm 3 \mathrm{DIM}(500 \mathrm{mg} /$ dose; Posilac; Monsanto Co., St Louis, MO), whereas bST was administered only to multiparous cows every $14 \mathrm{~d}$ until dry-off in the research farm. For submission to receive their first insemination, cows were synchronized using a Double-Ovsynch protocol as described by Souza et al. (2008). The first GnRH injection (G1) was administered at $53 \pm 3 \mathrm{DIM}$, and all cows received TAI at 80 \pm 3 DIM (Figure 1, panel A). Prostaglandin $\mathrm{F}_{2 \alpha}$ (dinoprost tromethamine; $25 \mathrm{mg} /$ dose; Lutalyse) was from Zoetis Inc. (New York, NY). The GnRH (gonadorelin diacetate tetrahydrate; $100 \mu \mathrm{g} /$ dose; Cystorelin) was from Merial Ltd. (Duluth, GA).

On the research farm, pregnancy diagnosis was performed $32 \mathrm{~d}$ after TAI using a portable scanner (Ibex Pro; E. I. Medical Imaging, Loveland, CO) fitted with a 7.5-MHz linear-array transducer. A positive pregnancy diagnosis was based on the presence of a corpus luteum $(\mathbf{C L})$ and an embryo with a heartbeat. On the commercial farms, pregnancy diagnosis was performed by palpation per rectum of the uterus $40 \mathrm{~d}$ after TAI.
Pregnancy status was not reconfirmed on 2 of the commercial farms; therefore, data to calculate pregnancy loss between first and second pregnancy diagnosis was only available for 1 commercial farm and the research farm. Pregnancy status was reconfirmed $70 \mathrm{~d}$ after TAI using ultrasound or palpation of the uterus. Cows diagnosed pregnant at first pregnancy examination and subsequently diagnosed not pregnant at the subsequent pregnancy examination were considered to have undergone pregnancy loss.

Blood Sampling and P4 Assay. Blood samples were collected via puncture of the median caudal vein or artery into 8-mL evacuated serum collection tubes (Vacuette; Greiner Bio-One North America Inc., Monroe, NC). Samples were collected from cows in the herds in which pregnancy status was reconfirmed $70 \mathrm{~d}$ after TAI. Samples were collected immediately before G1 of the Ovsynch-56 protocol (Figure 1, panel A). After collection, blood samples were refrigerated for $12 \mathrm{~h}$, and centrifuged at $1,600 \times g 20 \mathrm{~min}$ at $4^{\circ} \mathrm{C}$ for. Serum was harvested and stored at $-20^{\circ} \mathrm{C}$ until assayed for progesterone concentration using a solid-phase, no-extraction RIA (Coat-a-Count; Diagnostic Products Corp., Los

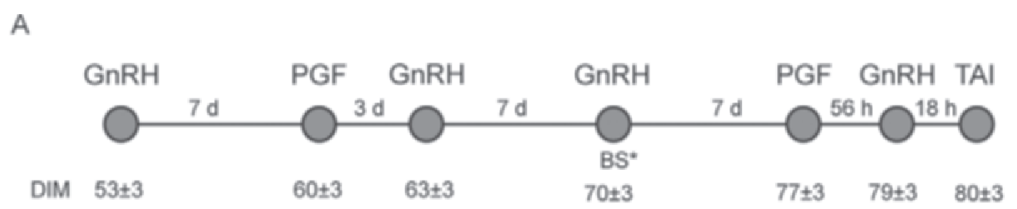

B

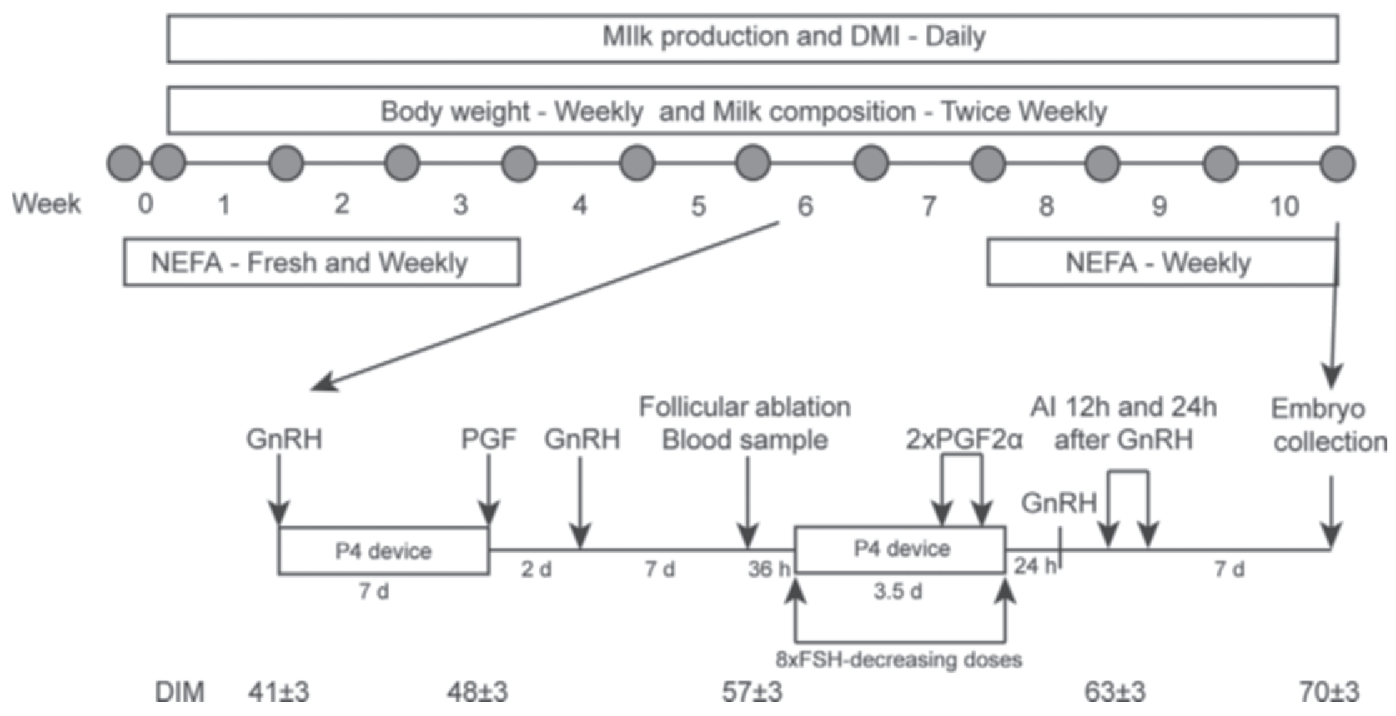

Figure 1. Schematic representation of the Double Ovsynch protocol used in experiments 1 and 2 (panel A), and diagram of sampling and the modified Double-Ovsynch protocol use in experiment 3 (panel B). PGF $=\mathrm{PGF}_{2 \alpha}$; BS = blood sample; TAI $=$ timed AI; P4 = progesterone. 
Angeles, CA). The average sensitivity for the 4 assays was $0.035 \mathrm{ng} / \mathrm{mL}$. The average intraassay coefficient of variation was $4.04 \%$, whereas the interassay coefficient of variation was $4.32 \%$, using a quality-control sample with $2.50 \mathrm{ng}$ of $\mathrm{P} 4 / \mathrm{mL}$.

$\boldsymbol{B} \boldsymbol{C S}$. Cows had their BCS evaluated by a single individual on each farm using a 5 -point scale with 0.25 increments: $1=$ thin to $5=$ fat (Edmonson et al., 1989) on the day of $\mathrm{AI} \pm 3 \mathrm{~d}$. For statistical analysis, cows were categorized according to BCS near AI as follows: $\leq 2.5,2.75,3.00$, and $\geq 3.25$. In addition, for some analyses, cows were further categorized as having low $(\leq 2.5)$ or high $(\geq 2.75)$ BCS near AI.

\section{Experiment 2}

Animals, Housing, and AI. Experiment 2 was conducted on 2 commercial farms in Central Wisconsin. Lactating dairy cows $(\mathrm{n}=1,887 ; 962$ primiparous and 925 multiparous) were housed in freestall barns bedded with mattresses and equipped with self-locking head gates at the feed line. Cows had ad libitum access to fresh feed and water. Cows were milked 3 times daily and were fed TMR (Supplementary Table S1; http:// dx.doi.org/10.3168/jds.2013-7809). All cows received bST every $14 \mathrm{~d}$ (500 mg/dose; Posilac; Monsanto Co.) beginning at $63 \pm 3$ DIM until dry-off. All cows were synchronized using a Double-Ovsynch protocol for first TAI as described in experiment 1 (Figure 1, panel A; Souza et al., 2008). Prostaglandin $\mathrm{F}_{2 \alpha}$ (dinoprost tromethamine; $25 \mathrm{mg} /$ dose; Lutalyse) was from Zoetis Inc. The GnRH (gonadorelin diacetate tetrahydrate; 100 $\mu \mathrm{g} /$ dose; Cystorelin) was from Merial Ltd. Pregnancy diagnosis was performed $40 \mathrm{~d}$ after TAI by palpation of the uterus, and pregnancy status was reconfirmed $70 \mathrm{~d}$ after TAI by palpation of the uterus.

BCS and Milk Production. The BCS of cows was evaluated twice by the same evaluator on the day of calving and $21 \mathrm{~d}$ later as described for experiment 1. Change in BCS was calculated by subtracting the BCS at calving from the BCS at $21 \mathrm{~d}$. For statistical analyses, cows were classified as losing, maintaining, or gaining BCS from calving to $21 \mathrm{~d}$ postpartum. Milk weights were recorded at each milking and stored in the on-farm computer software program (DairyCOMP 305; Valley Agricultural Software, Tulare, CA). Daily milk weights were extracted and used to calculate weekly average from calving to 21 DIM. Milk composition of the first official milk test was used to calculate ECM yield from calving to 21 DIM. Energy-corrected milk yield near AI was calculated using the average production during the week before TAI and the milk components of the official milk test closest to the AI date.

\section{Experiment 3}

Supplies and Semen. Prostaglandin $\mathrm{F}_{2 \alpha}$ (cloprostenol sodium; $500 \mu \mathrm{g}$ of cloprostenol/dose; Estrumate) was from Schering-Plough Animal Health (Union, NJ). The GnRH (gonadorelin diacetate tetrahydrate; $100 \mu \mathrm{g} /$ dose; Cystorelin) was from Merial Ltd. The FSH (NIH-FSH-P; $400 \mathrm{mg} /$ cow; Folltropin-V) from a single batch was from Bioniche Life Sciences Inc. (Belleville, ON, Canada). Intravaginal progesterone devices [Eazi-Breed controlled internal drug release (CIDR); containing $1.38 \mathrm{~g}$ of progesterone] were from Pfizer Animal Health (New York, NY). Lidocaine (lidocaine hydrochloride injectable $2 \% ; 5 \mathrm{~mL} /$ dose) was from Phoenix Pharmaceutical Inc. (St. Joseph, MO). Embryo filters (Miniflush Embryo System), y-tubing (Y-Junction Tubing), catheters (silicon ET catheter CH16/CH18, 2-way Foley, 30-mL balloon), embryocollection medium (BoviPRO Recovery Medium with PVA, 2 L), and holding medium (BoviPRO Holding Medium, with BSA) were from Minitube of America Inc. (Verona, WI). Semen was from Accelerated Genetics Inc. (Baraboo, WI). All breedings were performed with non-sexed frozen semen $\left(20 \times 10^{6}\right.$ sperm/straw $)$ from 2 Holstein sires with high genetic merit, proven outstanding field fertility (sire conception rates $\geq 1.5$ and over $90 \%$ reliability), and produced from a single ejaculate/sire to control for within-sire variation in semen quality. Sperm motility (sire $1=53 \%$ and sire 2 $=56 \%$ at $0 \mathrm{~h}$ ) was done objectively by a computerassisted semen analyzer (CEROS; Hamilton Thorne Inc., Beverly, MA). Sperm abnormalities (sire $1=9 \%$ and sire $2=14 \%$ ) and intact acrosome (sire $1=61 \%$ and sire $2=56 \%$ ) were evaluated under differential interference contrast optics $(\times 600)$.

Animals and Treatment Protocol. Lactating Holstein cows ( $\mathrm{n}=71 ; 27$ primiparous and 44 multiparous) were housed at the US Dairy Forage Research Center (Madison, WI) in individual tie-stalls from calving until $70 \pm 3$ DIM. Cows had ad libitum access to feed and water. Cows were milked twice daily and were individually fed TMR (Supplementary Table S2; http://dx.doi. org/10.3168/jds.2013-7809).

Cows were superovulated using a modified DoubleOvsynch protocol (Figure 1, panel B). At $41 \pm 3$ DIM, cows were presynchronized using an Ovsynch protocol with the addition of a CIDR between G1 and the $\mathrm{PGF}_{2 \alpha}$ injection (d 0: GnRH injection plus CIDR insert; d 7: $\mathrm{PGF}_{2 \alpha}$ injection and CIDR removal; $\mathrm{d}$ 9: $\mathrm{GnRH}$ injection). Seven days after the second GnRH injection (G2) of the presynchronization period, all follicles greater than $5 \mathrm{~mm}$ were ablated using ultrasoundguided aspiration (Aloka 900 equipped with a $13-\mathrm{MHz}$ convex-array transducer; Hitachi Aloka Medical Ltd., 
Wallingford, CT) as described by Bergfelt et al. (1994). Approximately $36 \mathrm{~h}$ after follicle ablation, a new CIDR device was inserted and 8 FSH treatments of decreasing dosages were administered at 12 -h intervals. Prostaglandin $\mathrm{F}_{2 \alpha}$ was administered concomitant to the fifth and seventh FSH treatments, and the CIDR device was removed at the last FSH treatment. Twenty-four hours after the last FSH treatment and CIDR removal, ovulation was induced using $200 \mu \mathrm{g}$ of GnRH.

AI and Ova/Embryo Recovery and Grading. All cows were inseminated and flushed by 2 technicians. Cows were inseminated twice at 12 and $24 \mathrm{~h}$ after GnRH treatment with semen from the same sire and by the same technician. Seven days after $\mathrm{GnRH}$ treatment, ova/embryos were recovered using a nonsurgical shallow uterine horn flushing technique as described by Sartori et al. (2003), and each uterine horn was flushed separately with 1 L of embryo-collection medium. Flushing media was filtered and recovered structures were evaluated under a stereomicroscope and graded according to International Embryo Transfer Society standards (Stringfellow and Givens, 2010). All embryo searching and grading procedures were performed by 1 technician who was blind to treatments.

DMI, BW, and Milk Production and Composition. Feed intake was measured daily from calving until the day of ova/embryo collection. Weekly, a TMR was sampled and the percentage DM calculated after drying for $48 \mathrm{~h}$ at $200^{\circ} \mathrm{C}$. The DMI was then calculated based on percentage DM multiplied by feed intake. Body weight was measured once per week, on Mondays after the afternoon milking at the exit of the milking parlor. Milk weights were recorded at each milking and stored in the on-farm computer software program (DairyCOMP 305; Valley Agricultural Software). Daily milk weights were extracted and used to calculate ECM yield during the study period. Milk composition was evaluated from milk samples collected at both milkings during 2 consecutive days per week. Milk composition was not evaluated during the first week postpartum; therefore, ECM was only estimated from the second week postpartum to the end of the study period.

Ultrasound, Blood Sampling, and Analysis. Ultrasound examination of the ovaries was performed at each GnRH injection (G1 and G2) of the presynchronization to evaluate cyclicity and presence of a dominant follicle $>10 \mathrm{~mm}$ in diameter at G2. On the day of follicular ablation, ovaries were evaluated for the presence of CL. The number of CL was determined on the day of flushing by the same technician.

Blood samples $(\sim 8 \mathrm{~mL})$ for NEFA analysis were collected into evacuated plasma collection tubes containing K3 EDTA by puncture of the coccygeal vein or artery before feeding. Blood samples were collected within 24 to $48 \mathrm{~h}$ after calving and then weekly until the third week postpartum and weekly from follicular ablation until embryo collection. Blood samples for analysis of P4 were collected immediately before follicular ablation, as described for NEFA samples. After collection, blood samples were immediately centrifuged at 1,600 $\times$ $g$ for $20 \mathrm{~min}$ at $4^{\circ} \mathrm{C}$. Plasma was harvested and stored at $-20^{\circ} \mathrm{C}$ until assayed. The NEFA concentrations were analyzed using the acetyl-CoA synthase, acyl-CoA oxidase, and peroxidase method (HR Series NEFA-2; Wako Pure Chemical Industries Ltd., Richmond, VA). The P4 concentrations were analyzed using a solid-phase, no-extraction RIA (Coat-a-Count; Diagnostic Products Corp.). The sensitivity of the $\mathrm{P} 4$ assay was $0.04 \mathrm{ng} / \mathrm{mL}$ and the coefficient of variation for the assay was $2.2 \%$.

\section{Definitions and Statistical Analysis}

All statistical analyses were performed using SAS computational software (version 9.3 of SAS for Windows; SAS Institute Inc., Cary, NC). A significant difference between the levels of a classification variable was considered at $P \leq 0.05$, whereas differences between $P$ $>0.05$ and $P \leq 0.15$ were considered a statistical tendency. Data are presented as means \pm standard error of the mean, obtained using PROC MEANS of SAS.

Experiment 1. Variables with a binomial distribution, such as pregnancies per AI (P/AI), pregnancy loss, and proportion of cows with low $\mathrm{P} 4$ concentrations at G1, were analyzed by logistic regression using PROC GLIMMIX of SAS. For P/AI at first and second pregnancy diagnosis, and pregnancy loss, the initial model contained the following categorical explanatory variables as fixed effects: parity (primiparous vs. multiparous), BCS level, and their interaction. Farm and cow were included as random effects in the model. Selection of the fixed effects model that best fit the data for each variable of interest was performed by finding the model with the lowest value for the Akaike information criterion using a backward elimination procedure that sequentially removed all variables with $P>0.15$ from the model. Both BCS level and parity were forced to remain in each model. Parity was forced into the final statistical models because primiparous cows have greater $\mathrm{P} / \mathrm{AI}$ compared with multiparous cows after synchronization of ovulation and TAI using a DoubleOvsynch protocol (Souza et al., 2008; Herlihy et al., 2012; Giordano et al., 2013). Because no significant interaction between parity and BCS category was detected for any of the variables analyzed, all final models included the fixed effects of BCS category and parity, and the random effects of cow and farm. A contrast statement was used to compare $\mathrm{P} / \mathrm{AI}$ between cows with low $(\leq 2.50)$ and high $(\geq 2.75)$ BCS near AI. 
Survival analysis was conducted to evaluate the effect of low $(\leq 2.50)$ versus high $(\geq 2.75)$ BCS at first postpartum TAI on the hazard ratio (HR) of pregnancy up to 300 DIM using PROC PHREG of SAS to create Cox semiparametric proportional hazard models. The outcome variable for the model was the DIM at which cows became pregnant (based on 70-d pregnancy diagnosis). Right censoring occurred for cows that left the herd due to live culling, death, or designation of the cows as "do not breed." The model included parity and BCS at first postpartum TAI as categorical explanatory variables. Kaplan-Meier survival analysis curves were constructed to illustrate the rate at which cows became pregnant using the Kaplan-Meier survival analysis features of SigmaPlot software (version 12.5; Systat Software Inc., San Jose, CA).

Experiment 2. Cows were classified into 3 categories according to BCS change from calving to $3 \mathrm{wk}$ postpartum. Data were analyzed by logistic regression, using PROC GLIMMIX of SAS. For P/AI at first pregnancy and second pregnancy diagnosis, and pregnancy loss, the initial model contained the following categorical explanatory variables as fixed effects: parity (primiparous vs. multiparous), level of BCS loss, and the interaction between BCS loss and parity. Cow and farm were included as random effects. Selection of the fixed-effects model that best fit the data for each variable of interest was performed similar to that described for experiment 1. All final models included the fixed effects of level of BCS loss and parity, and the random effects of cow and farm. Differences in ECM from calving to 21 DIM among groups were evaluated using PROC MIXED of SAS, using a model containing the fixed effect of group, week, parity and the interactions of group by week and parity by group, with cow included as a random effect. Due to repeated measures within each cow, a repeated statement was used to account for autocorrelations by modeling the first-order autoregressive between sequential measurements. Differences in ECM near TAI among groups were evaluated using PROC MIXED of SAS, using a model containing the fixed effect of group, parity, and the interactions of parity by group, with cow included as a random effect.

Survival analysis was conducted to evaluate the effect of BCS change (gained, maintained, or lost) from calving to $21 \mathrm{~d}$ postpartum on the HR of time to pregnancy, similar to experiment 1 . The model included parity and BCS change from calving to $21 \mathrm{~d}$ postpartum as categorical explanatory variables. Kaplan-Meier survival analysis curves were constructed as described for experiment 1.

Experiment 3. The CORR procedure of SAS was used to assess the correlations among the following measures: NEFA at first week postpartum, NEFA near
$\mathrm{AI}$, percentage of BW change from calving to third week postpartum, calving to ninth week postpartum, percentage of fertilized structures, percentage of degenerated structures, and percentage of transferable structures. Because percentage of BW change from calving to third week postpartum was found to have the highest correlation $(P=0.007)$ with embryo quality, cows were ranked by percentage BW change from first to third week postpartum and divided into quartiles. Data were examined for normality using the Shapiro-Wilk test. Data that were not normally distributed were transformed to natural logarithms or ranks. Differences in percentage BW change, NEFA concentrations, and DMI, and ECM yield among quartiles were evaluated using PROC MIXED of SAS, using a model containing the fixed effect of quartile, week, parity, and the interactions of quartile by week and parity by quartile, with cow included as a random effect. Due to repeated measures within each cow, a repeated statement was used to account for autocorrelations by modeling the first-order autoregressive or spatial power between sequential measurements. Selection of the fixed effects model that best fit the data for each variable of interest was performed similarly to that described for experiment 1.

Cows with 3 or more CL at embryo collection assessed by ultrasound were considered to have responded to superovulatory treatment. Because we wanted to test our hypothesis only for superovulated cows, any cows with less than $3 \mathrm{CL}$ on the day of embryo collection and cows without ova/embryos recovered (total of 5 cows) were excluded from further analyses. The percentage of fertilized structures was calculated by dividing the total number of cleaved structures by the total number of structures; percentage freezable embryos was calculated by dividing the total number of embryos of grade 1 and 2 by the total number of structures; percentage transferable was calculated by dividing the total number of grade- $1,-2$, and -3 embryos by the total number of structures; and percentage degenerated embryos was calculated by dividing the total number of degenerated embryos by the total number of structures. The percentage freezable from the fertilized embryos was calculated by dividing the number of grade- 1 and -2 embryos by the total number of fertilized structures; percentage transferable from the fertilized embryos was calculated by dividing the number of grade- $1,-2$, and -3 embryos by the total number of fertilized structures; and percentage degenerated from the fertilized embryos was calculated by dividing the number of degenerated embryos by the total number of fertilized structures. The GLIMMIX procedure of SAS was used to compare embryo characteristics, using cow as the experimental unit. The initial model contained the variables for fixed 
effects of: quartile, parity, breeding sire, AI technician, and the interaction of quartile by parity. Model selection was performed using a stepwise backward elimination procedure that removed variables with $P>0.15$ from the model. The final logistic regression models included quartile as fixed effect, and cow as a random effect.

\section{RESULTS}

\section{Experiment 1}

Overall, $23.6 \%(260 / 1,103)$ of the cows were classified with a BCS $\leq 2.50$, whereas $31.1 \%(343 / 1,103), 23.5 \%$ $(259 / 1,103)$, and $21.8 \%(241 / 1,103)$ of the cows were classified with a BCS of $2.75,3.00$, and $\geq 3.25$, respectively (Table 1). Overall, $47.1 \%(520 / 1,103)$ of the cows were pregnant at first pregnancy examination. Primiparous cows had more $(P=0.003) \mathrm{P} / \mathrm{AI}$ compared with multiparous cows (52.7 vs. $43.1 \%$, respectively).

Based on an analysis that included all BCS categories, $\mathrm{P} / \mathrm{AI}$ tended to differ $(P=0.10)$ by $\mathrm{BCS}$, with fewer $\mathrm{P} / \mathrm{AI}$ for cows with $\mathrm{BCS} \leq 2.50$, intermediate for cows with $\mathrm{BCS}=2.75$ and $\mathrm{BCS}=3.0$, and greatest for cows with $\mathrm{BCS} \geq 3.25$ (Table 1 ). In addition, when cows were categorized as having high $(\geq 2.75)$ or low $(\leq 2.50)$ BCS near AI, P/AI differed between BCS categories and were greater $(P=0.03)$ for cows with high BCS compared with cows with low BCS (49.2 vs. $40.4 \%$, respectively).

In the 2 herds that had a second pregnancy examination, $\mathrm{P} / \mathrm{AI}$ at the second examination averaged $42.8 \%$ $(266 / 621)$ and differed between parity groups. Primiparous cows had more $(P=0.008) \mathrm{P} / \mathrm{AI}$ compared with multiparous cows (49.8 vs. $38.4 \%$, respectively). Pregnancies per AI also differed $(P=0.05)$ among BCS levels, and were least for cows with BCS $\leq 2.50$, intermediate for cows with $\mathrm{BCS}=2.75$ and $\mathrm{BCS}=$ 3.0 , and greatest for cows with $\mathrm{BCS} \geq 3.25$ (Table 1). In addition, $\mathrm{P} / \mathrm{AI}$ differed by $\mathrm{BCS}(P=0.02)$ when cows were classified into high versus low BCS (46.0 vs. $34.5 \%$, respectively). The effect of BCS on P/AI at first and second pregnancy examination was similar for primiparous and multiparous cows, as demonstrated by a nonsignificant interaction between parity and BCS ( $P=0.44$ and $P=0.46$, respectively). Pregnancy loss averaged $11.9 \%(36 / 302)$ and did not differ among BCS levels $(P=0.40$; Table 1$)$ or category $(P=0.31 ; 15.7$ vs. $10.8 \%$ for low and high BCS category) or between parities $(P=0.19 ; 9.0$ vs. $14.1 \%$, for primiparous and multiparous cows).

In the 2 herds with $\mathrm{P} 4$ measurements, the mean P4 concentration at the initiation of the breeding Ovsynch protocol (G1) was lower $(P=0.04)$ for cows with low

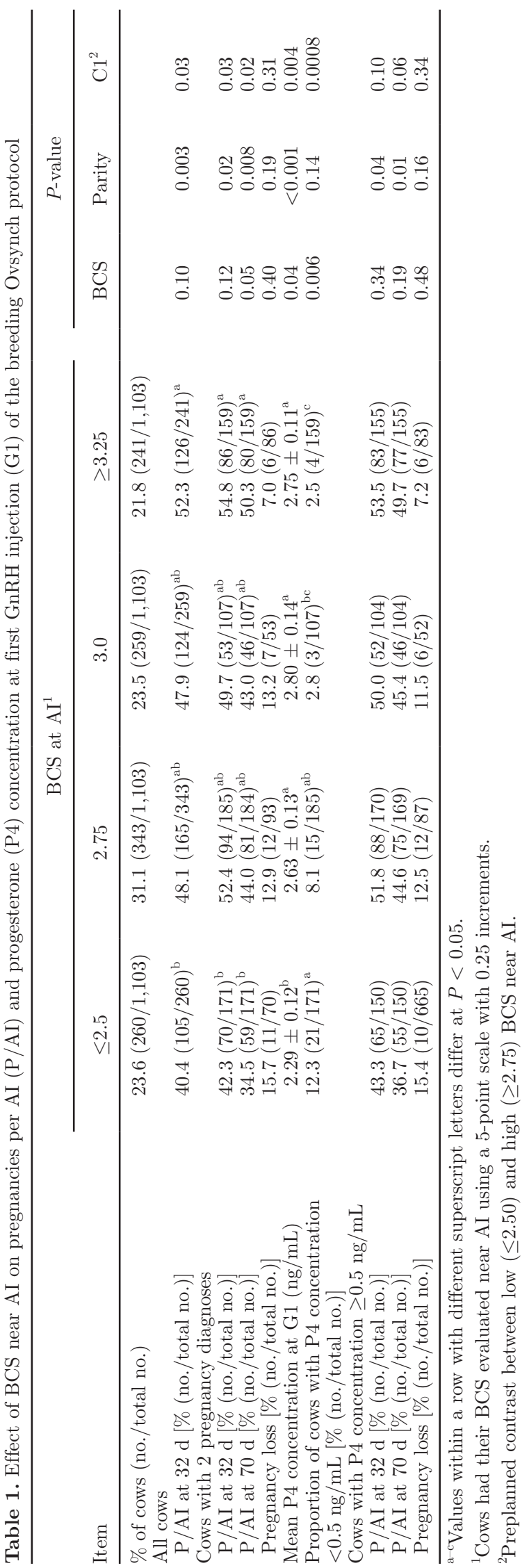


BCS $(\leq 2.5)$ than for all other BCS categories. Overall, $6.9 \%(43 / 622)$ of the cows had low P4 concentration $(<0.5 \mathrm{ng} / \mathrm{mL})$ at G1. The proportion of cows with low $\mathrm{P} 4$ concentration $(<0.5 \mathrm{ng} / \mathrm{mL})$ was greater $(P=$ $0.006)$ for cows with $\mathrm{BCS} \leq 2.5$ than the other BCS levels (Table 1$)$ and differed between BCS categories $(P$ $=0.0008 ; 12.3$ vs. $4.8 \%$ for low and high BCS category, respectively). When only cows with $\mathrm{P} 4$ concentrations $\geq 0.5 \mathrm{ng} / \mathrm{mL}$ at $\mathrm{G} 1$ were considered for analysis, P/AI did not differ among BCS levels at the first $(P=0.34)$ or second $(P=0.19)$ pregnancy examination (Table 1) but tended to differ between BCS categories (high vs. low BCS) at first (51.9 vs. $43.3 \% ; P=0.10)$ and second (46.3 vs. $36.7 \% ; P=0.06$ ) pregnancy examinations. Furthermore, in cows with $\mathrm{P} 4$ concentration $\geq 0.5$ $\mathrm{ng} / \mathrm{mL}, \mathrm{P} / \mathrm{AI}$ were greater for primiparous compared with multiparous cows at first (55.2 vs. $46.1 \% ; P=$ 0.04 ) and second (50.4 vs. $39.4 \% ; P=0.01$ ) pregnancy examinations. Pregnancy loss between first and second pregnancy examination did not differ between parities $(P=0.16 ; 8.7$ vs. $14.4 \%$ for primiparous and multiparous cows, respectively), among BCS levels $(P=0.48$; Table 1$)$, or between BCS categories $(P=0.34 ; 15.4$ vs. $9.9 \%$ for cows with $\mathrm{BCS} \leq 2.50$ and $\mathrm{BCS} \geq 2.75$, respectively).

The median calving-to-pregnancy interval differed (log-rank test, $P=0.01$ ) between BCS groups and was $113 \mathrm{~d}$ for cows with high BCS compared with $146 \mathrm{~d}$ for cows with low BCS at first postpartum TAI (Figure 2). Furthermore, cows with high BCS at first postpartum TAI were 1.3 times more likely to conceive by 300 DIM compared with cows with low BCS $(\mathrm{HR}=1.3 ; P=$ 0.02).

\section{Experiment 2}

Overall, $7.3 \%$ of cows lost 0.5 or more BCS points $(139 / 1,887)$. No difference existed between cows that lost 0.5 or more BCS points compared with those that lost 0.25 BCS points in $\mathrm{P} / \mathrm{AI}$ at $40 \mathrm{~d}$ (27.3 vs. $24.6 \%$, respectively; $P>0.15)$ or at $70 \mathrm{~d}$ (24.6 vs. $22.3 \%$, respectively; $P>0.15$ ) after TAI, or in pregnancy loss between first and second pregnancy examination (7.9 vs. $9.4 \%$, respectively; $P>0.15)$. Therefore, we combined these cows into a single group for all subsequent analyses (i.e., cows that lost BCS between calving and 21 DIM). Overall, the proportion of cows that lost, maintained, and gained BCS between calving and 21 DIM was 41.8, 35.8, and 22.4, respectively (Table 2). Production of ECM from calving to 21 DIM did not differ $(P=0.30)$ among cows that lost, maintained, or gained BCS (Tables 2 and 3). Near TAI, production of ECM was similar among primiparous $(P=0.47)$ and among multiparous $(P=0.40)$ cows that lost, maintained, or gained BCS (Table 3).

At the 40-d pregnancy examination (Table 2), P/AI differed $(P<0.001)$ dramatically among BCS change categories and was greater for cows that gained BCS $(83.5 \%$; 353/423), intermediate for cows that maintained BCS $(38.2 \% ; 258 / 675)$, and least for cows that lost BCS $(25.1 \% ; 198 / 789)$. Similarly, at the $70-d$ pregnancy diagnosis (Table 2), a dramatic effect of BCS change on $\mathrm{P} / \mathrm{AI}(P<0.001)$ existed but no effect on pregnancy loss $(P=0.34)$. Interestingly, the association between BCS change and $\mathrm{P} / \mathrm{AI}$ differed between the 2 farms (Table 2). On farm $1, \mathrm{P} / \mathrm{AI}$ at $40 \mathrm{~d}$ and at $70 \mathrm{~d}$ after TAI were similar $(P=0.60$ and $P=0.35$, respectively) among BCS change categories; however, on farm 2, P/AI at $40 \mathrm{~d}$ and at $70 \mathrm{~d}$ after TAI differed $(P<0.001$ for both $)$ dramatically among BCS change categories and was greater for cows that gained BCS, intermediate for cows that maintained BCS, and least for cows that lost BCS (Table 2). On both farms, pregnancy loss was similar among BCS change categories (Table 2). The proportion of cows gaining BCS was greater for farm $2(33.5 \%$; 358/1,070) than for farm 1 $(8.0 \% ; 65 / 817)$, whereas the proportion of cows maintaining BCS was greater on farm $1(49.5 \%$; 405/817) than farm $2(25.2 \% ; 270 / 1,070)$. The proportion of primiparous cows did not differ $(P=0.88)$ between farms (farm $1=50.8 \%$ vs. farm $2=51.1 \%$ ).

An effect of parity (primiparous vs. multiparous) on BCS was detected at parturition $(2.82$ vs. $2.98 ; P<$

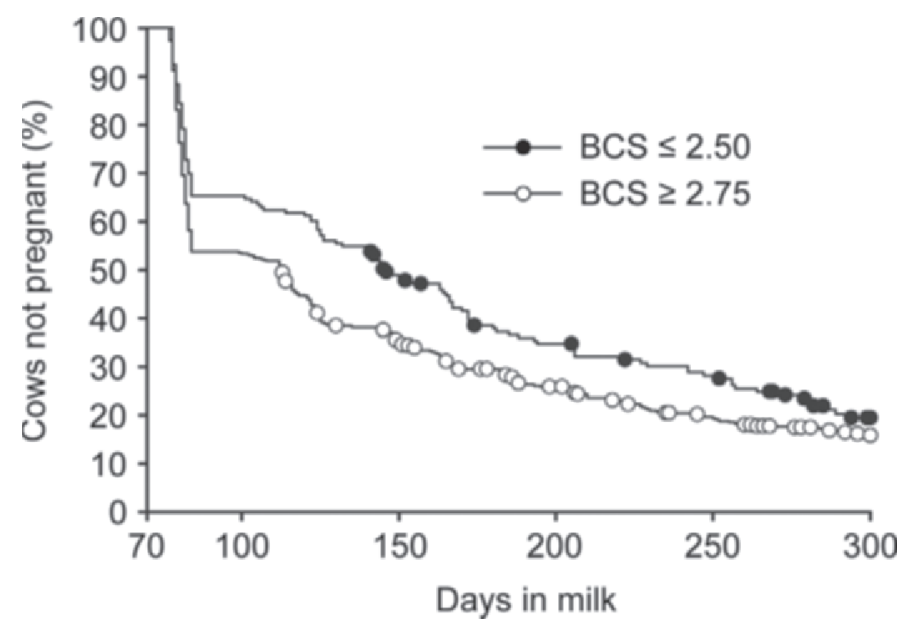

Figure 2. Kaplan-Meier survival analysis of calving-to-pregnancy interval for cows with $\mathrm{BCS} \leq 2.50$ (closed circles) or BCS $\geq 2.75$ (open circles) at first postpartum timed AI (TAI). Cows with BCS $\leq 2.50$ at first postpartum TAI had a median calving-to-conception interval of $146 \mathrm{~d}$ compared with $113 \mathrm{~d}$ for cows with BCS $\geq 2.75$. The symbols on each line represent a censoring event (cow removed from analysis due to death, culling, or designation as "do not breed"). 
Table 2. Effect of BCS change (mean \pm SEM) on pregnancies per AI (P/AI) for cows on farm 1 and 2 classified as losing, maintaining, or gaining BCS from parturition to 3 wk postpartum

\begin{tabular}{|c|c|c|c|c|c|c|}
\hline \multirow[b]{2}{*}{ Item } & \multicolumn{3}{|c|}{ BCS change $^{1}$} & \multicolumn{3}{|c|}{$P$-value } \\
\hline & Lost & Maintained & Gained & BCS change & Parity & $\begin{array}{l}\text { BCS change } \\
\times \text { parity }\end{array}$ \\
\hline$\%$ of cows (n/total no.) & $41.8(789 / 1,887)$ & $35.8(675 / 1,887)$ & $22.4(423 / 1,887)$ & & & \\
\hline $\mathrm{P} / \mathrm{AI}$ at $40 \mathrm{~d}[\%$ (no./total no.) $]$ & $25.1(198 / 789)^{\mathrm{c}}$ & $38.2(258 / 675)^{\mathrm{b}}$ & $83.5(353 / 423)^{a}$ & $<0.001$ & $<0.001$ & 0.37 \\
\hline $\mathrm{P} / \mathrm{AI}$ at $70 \mathrm{~d}[\%$ (no./total no.) $]$ & $22.8(180 / 789)^{\mathrm{c}}$ & $36.0(243 / 675)^{\mathrm{b}}$ & $78.3(331 / 423)^{\mathrm{a}}$ & $<0.001$ & $<0.001$ & 0.19 \\
\hline BCS at 21 DIM & $2.64 \pm 0.01^{\mathrm{c}}$ & $2.89 \pm 0.02^{\mathrm{b}}$ & $3.10 \pm 0.02^{\mathrm{a}}$ & $<0.001$ & $<0.001$ & 0.06 \\
\hline $\operatorname{ECM}^{2}(\mathrm{~kg} / \mathrm{d})$ & $30.9 \pm 0.4$ & $31.5 \pm 0.4$ & $28.7 \pm 0.4$ & 0.30 & 0.002 & 0.74 \\
\hline \multicolumn{7}{|l|}{ Farm 1} \\
\hline$\%$ of cows (n/total no.) & $42.5(347 / 817)$ & $49.5(405 / 817)$ & $8.0(65 / 817)$ & & & \\
\hline $\mathrm{P} / \mathrm{AI}$ at $40 \mathrm{~d}[\%$ (no./total no.) $]$ & $36.0(125 / 347)$ & $37.5(152 / 405)$ & $43.1(28 / 65)$ & 0.60 & $<0.001$ & 0.95 \\
\hline $\mathrm{P} / \mathrm{AI}$ at $70 \mathrm{~d}[\%$ (no./total no.) $]$ & $32.3(112 / 347)$ & $35.8(145 / 405)$ & $41.5(27 / 65)$ & 0.35 & $<0.001$ & 0.99 \\
\hline Pregnancy loss [\% (no./total no.)] & $10.4(13 / 125)$ & $4.6(7 / 152)$ & $3.6(1 / 28)$ & 0.16 & 0.97 & 0.57 \\
\hline $\mathrm{P} / \mathrm{AI}$ at $40 \mathrm{~d}[\%$ (no./total no.) $]$ & $16.5(73 / 442)^{\mathrm{c}}$ & $39.3(106 / 270)^{\mathrm{b}}$ & $90.8(325 / 358)^{a^{a}}$ & $<0.001$ & 0.04 & 0.42 \\
\hline $\mathrm{P} / \mathrm{AI}$ at $70 \mathrm{~d}[\%$ (no./total no.) & $15.4(68 / 442)^{\mathrm{c}}$ & $36.3(98 / 270)^{\mathrm{b}}$ & $84.9(304 / 358)^{\mathrm{a}}$ & $<0.001$ & 0.02 & 0.24 \\
\hline Pregnancy loss [\% (no./total no.)] & $6.8(5 / 73)$ & $7.5(8 / 106)$ & $6.5(21 / 325)$ & 0.89 & 0.97 & 0.27 \\
\hline BCS at parturition & $2.95 \pm 0.02^{\mathrm{a}}$ & $2.88 \pm 0.02^{\mathrm{ab}}$ & $2.85 \pm 0.02^{b}$ & 0.007 & $<0.001$ & 0.48 \\
\hline BCS at 21 DIM & $2.67 \pm 0.02^{\mathrm{c}}$ & $2.88 \pm 0.02^{\mathrm{b}}$ & $3.10 \pm 0.02^{\mathrm{a}}$ & $<0.001$ & $<0.001$ & 0.52 \\
\hline $\operatorname{ECM}^{2}(\mathrm{~kg} / \mathrm{d})$ & $28.4 \pm 0.4$ & $27.7 \pm 0.6$ & $27.9 \pm 0.5$ & 0.37 & $<0.001$ & 0.52 \\
\hline
\end{tabular}

${ }^{\mathrm{a}-\mathrm{c}}$ Values within a row with different superscript letters differ at $P<0.05$.

${ }^{1}$ Cows had their BCS evaluated at calving and at 21 DIM using a 5-point scale with 0.25 increments.

${ }^{2}$ Average ECM from calving to 21 DIM.

$0.001)$ and at 21 DIM (2.76 vs. 2.90; $P<0.001)$ and on $\mathrm{P} / \mathrm{AI}$ at $40 \mathrm{~d}(50.1$ vs. $35.4 \% ; P<0.001)$ and 70 d (47.0 vs. $32.6 \% ; P<0.001)$ after TAI but no effect
$(P=0.41)$ on pregnancy loss (Table 3$)$ was detected. The proportion of primiparous cows differed $(P=0.02)$ among BCS change categories, and was greater for

Table 3. Effect of BCS change (mean \pm SEM) from parturition to 3 wk postpartum on pregnancies per AI (P/AI) for primiparous and multiparous cows

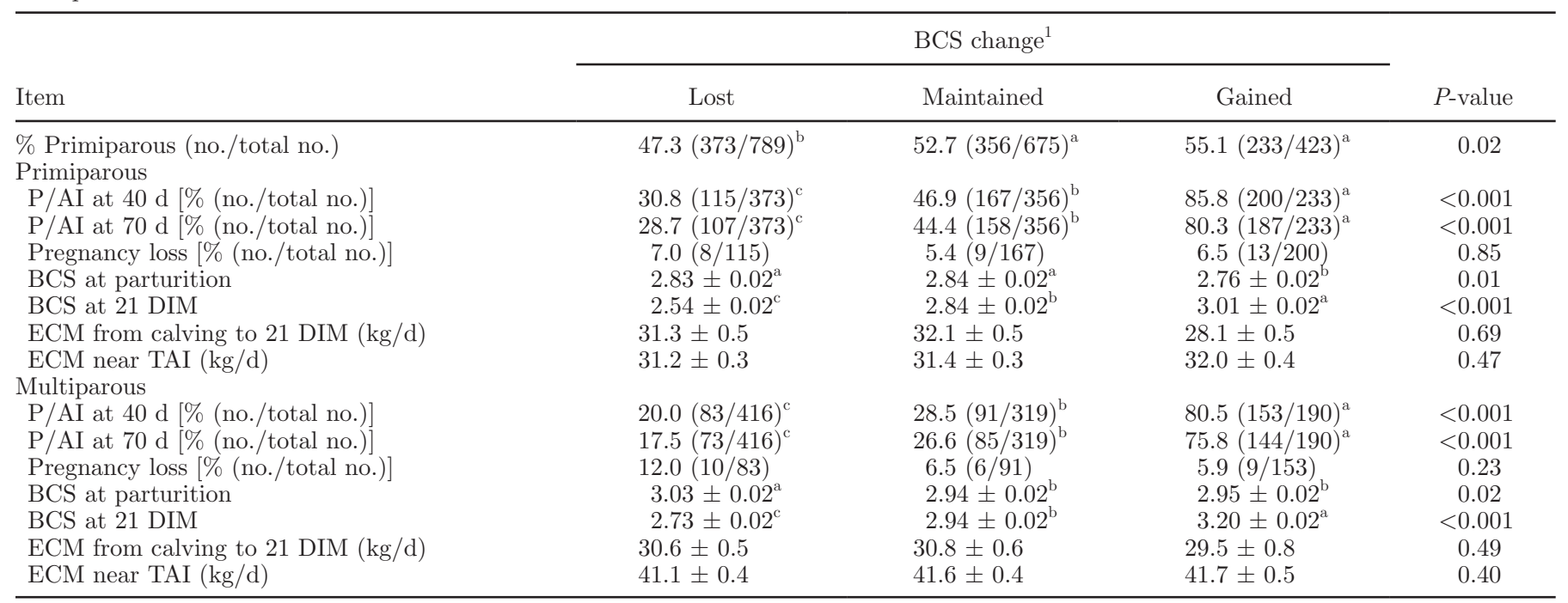

${ }^{a-c}$ Values within a row with different superscript letters differ at $P<0.05$.

${ }^{1}$ Cows had their BCS evaluated at calving and at 21 DIM using a 5-point scale with 0.25 increments. 


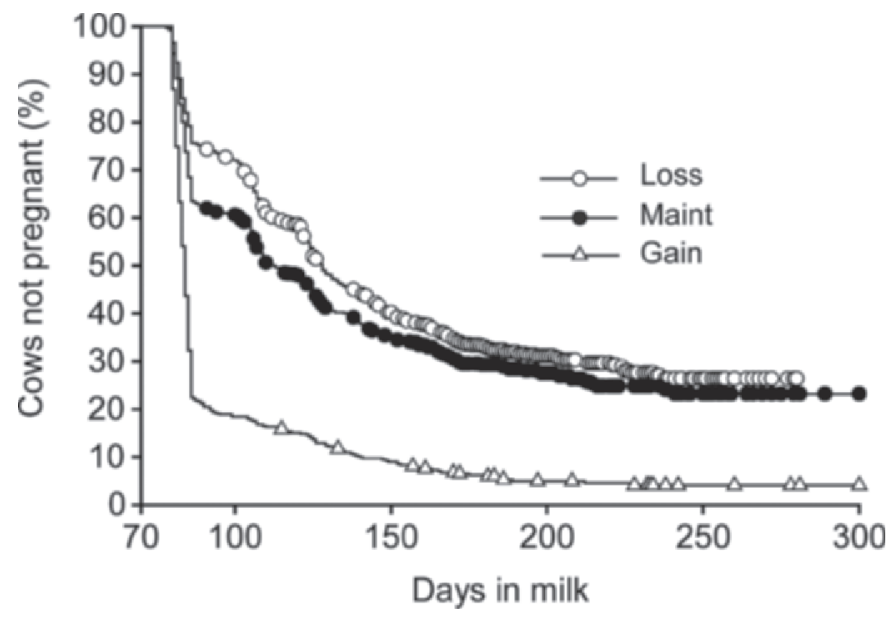

Figure 3. Kaplan-Meier survival analysis of calving-to-pregnancy interval for cows that gained (open triangles), maintained (closed circles), or lost (open circles) BCS between calving and $21 \mathrm{~d}$ postpartum. Cows gaining BCS between calving and $21 \mathrm{~d}$ postpartum had a median calving-to-conception interval of $84 \mathrm{~d}$, compared with $113 \mathrm{~d}$ for cow maintaining BCS and $128 \mathrm{~d}$ for cows losing BCS between calving and $21 \mathrm{~d}$ postpartum. The symbols on each line represent a censoring event (cow removed from analysis due to death, culling, or designation as "do not breed").

cows that gained and maintained BCS and least for cows that lost BCS (Table 3). For primiparous cows, BCS change had a dramatic effect on $\mathrm{P} / \mathrm{AI}$ at the $40-\mathrm{d}$ $(P<0.001)$ and $70-\mathrm{d}(P<0.001)$ pregnancy examinations. Similarly for multiparous cows, BCS change had a dramatic effect on $\mathrm{P} / \mathrm{AI}$ at the $40-\mathrm{d}(P<0.001)$ and $70-\mathrm{d}(P<0.001)$ pregnancy examinations (Table 3$)$. No effect of BCS change on pregnancy loss was detected in either primiparous $(P=0.85)$ or multiparous $(P=$ $0.23)$ cows.

The median calving-to-pregnancy interval differed (log-rank test, $P<0.001$ ) between BCS groups and was 84, 113, and $128 \mathrm{~d}$ for cows that gained, maintained, and lost BCS between calving and $21 \mathrm{~d}$ postpartum, respectively (Figure 3 ). In addition, cows that gained BCS between calving and $21 \mathrm{~d}$ postpartum were 3.0 and 2.5 times more likely to conceive by 300 DIM compared with cows that lost and maintained BCS $[\mathrm{HR}=3.0$ $(P<0.001)$ and $\mathrm{HR}=2.5(P<0.001)$, respectively].
Moreover, cows that maintained BCS between calving and $21 \mathrm{~d}$ postpartum were 1.2 times more likely to conceive by 300 DIM compared with cows that lost BCS $[\mathrm{HR}=1.2(P=0.01)]$.

\section{Experiment 3}

Cows $(\mathrm{n}=5)$ were eliminated from the analysis if they had no ova/embryos recovered and the remaining 66 cows (26 primiparous and 40 multiparous) were analyzed. An initial logistic regression analysis was done on NEFA concentrations (first and third week postpartum) and percentage BW change (calving to third or calving to ninth week postpartum) on fertilization, percentage degenerate, and percentage transferable embryos considered for statistical analysis (Table 4). As expected, clear relationships existed among NEFA concentrations and percentage of BW change. For example, percentage of BW change from calving to third week was correlated with NEFA concentration at the first week $(\mathrm{r}=$ $-0.32)$ or third week $(r=-0.30)$ and percentage BW change from calving to the ninth week was correlated with NEFA at the third week $(\mathrm{r}=-0.48)$ and percentage BW change from calving to the third week ( $\mathrm{r}$ $=0.73)$. In addition, percentage transferable embryos was correlated with percentage fertilized $(r=0.69)$ and percentage degenerated $(\mathrm{r}=-0.64)$. Of particular interest, percentage BW change from calving to the third week was correlated with percentage degenerated $(\mathrm{r}=$ $-0.33)$ and percentage transferable embryos $(\mathrm{r}=0.30)$. Therefore, cows were ranked by percentage BW change from the first to third week postpartum and divided into quartiles $(\mathbf{Q} ; \mathrm{n}=16,17,16$, and 17, for Q1, Q2, Q3, and Q4, respectively; Table 5).

By design, percentage BW change from the first to third week postpartum differed among quartiles $(P<$ 0.001; Table 5; Figure 4, panel A). An interesting quartile by week interaction $(P<0.001$; Figure 4 , panel A) was detected. Cows in Q1 did not lose BW after calving but rather BW increased from the second to third week postpartum and remained constant until the seventh week postpartum when BW began to increase gradually until the end of the study period (Figure 4;

Table 4. Correlations ( $P$-values in parentheses) among NEFA concentrations at wk 1 and 3 postpartum, percentage transferable (\% Trans), percentage degenerated (\% Deg), percentage fertilized ova (\% Fert), and percentage BW change (BWC) between calving and wk 3 and 9 postpartum

\begin{tabular}{lccccrrr}
\hline Item & NEFA, wk 1 & NEFA, wk 3 & BWC, wk 3 & BWC, wk 9 & \% Fert & \% Deg & \% Trans \\
\hline NEFA, wk 1 & 1 & $0.29(0.02)$ & $-0.32(0.009)$ & $-0.23(0.07)$ & $0.01(0.94)$ & $0.27(0.03)$ & $-0.19(0.13)$ \\
NEFA, wk 3 & & 1 & $-0.30(0.01)$ & $-0.48(<0.001)$ & $-0.06(0.61)$ & $0.16(0.21)$ & $-0.17(0.18)$ \\
BWC, wk 3 & & & 1 & $0.73(<0.001)$ & $0.08(0.54)$ & $-0.33(0.007)$ & $0.30(0.01)$ \\
BWC, wk 9 & & & & $0.13(0.31)$ & $-0.28(0.02)$ & $0.31(0.01)$ \\
\% Fert & & & & 1 & $0.11(0.35)$ & $0.69(<0.001)$ \\
\% Deg & & & & & 1 & $-0.64(<0.001)$ \\
\hline
\end{tabular}


Table 5. Proportion of primiparous and multiparous cows, percentage BW change, NEFA concentrations, ECM yield, and DMI for cows divided into quartiles based on percentage BW change from parturition to $3 \mathrm{wk}$ postpartum (values presented as mean \pm SEM)

\begin{tabular}{|c|c|c|c|c|c|c|c|}
\hline \multirow[b]{2}{*}{ Item } & \multicolumn{4}{|c|}{ Quartile group ${ }^{1}$} & \multicolumn{3}{|c|}{$P$-value } \\
\hline & $\begin{array}{l}\text { Lost BW+: } \\
\text { fourth quartile }\end{array}$ & $\begin{array}{l}\text { Lost BW: } \\
\text { third quartile }\end{array}$ & $\begin{array}{l}\text { Maintained BW: } \\
\text { second quartile }\end{array}$ & $\begin{array}{l}\text { Gained BW: } \\
\text { first quartile }\end{array}$ & Quartile & Week & $\begin{array}{l}\text { Quartile } \\
\times \text { week }\end{array}$ \\
\hline $\mathrm{n}$ & 17 & 16 & 17 & 16 & & & \\
\hline Primiparous [no. (\%)] & $4(23.5)$ & $6(37.5)$ & $8(47.1)$ & $8(50)$ & 0.44 & - & - \\
\hline Initial BW (kg) & $644.0 \pm 19.7^{\mathrm{a}}$ & $638.6 \pm 25.3^{\mathrm{a}}$ & $599.8 \pm 18.7^{\mathrm{a}}$ & $550.3 \pm 16.7^{\mathrm{d}}$ & 0.03 & - & - \\
\hline Initial BW, primiparous $(\mathrm{kg})$ & $543.7 \pm 8.7^{\mathrm{ab}}$ & $539.8 \pm 12.0^{\mathrm{ab}}$ & $544.0 \pm 22.0^{\mathrm{a}}$ & $502.1 \pm 7.6^{\mathrm{b}}$ & 0.12 & - & - \\
\hline Initial BW, multiparous (kg) & $674.8 \pm 18.4$ & $697.8 \pm 24.8$ & $649.4 \pm 17.2$ & $598.5 \pm 21.8$ & 0.18 & - & - \\
\hline BW change from first to third week (\%) & $-7.49 \pm 0.47^{\mathrm{d}}$ & $-2.96 \pm 0.17^{\mathrm{c}}$ & $-0.96 \pm 0.18^{\mathrm{b}}$ & $2.46 \pm 0.72^{\mathrm{a}}$ & $<0.001$ & - & - \\
\hline BW change ${ }^{2}(\%)$ & $-6.85 \pm 0.32^{\mathrm{d}}$ & $-3.50 \pm 0.30^{\mathrm{c}}$ & $-0.07 \pm 0.25^{\mathrm{b}}$ & $2.39 \pm 0.32^{\mathrm{a}}$ & $<0.001$ & $<0.001$ & $<0.001$ \\
\hline $\mathrm{NEFA}^{2}(\mathrm{mEq} / \mathrm{L})$ & $387.9 \pm 27.7$ & $299.7 \pm 19.8$ & $254.7 \pm 18.2$ & $270.0 \pm 19.1$ & 0.11 & $<0.001$ & 0.002 \\
\hline NEFA, first week $(\mathrm{mEq} / \mathrm{L})$ & $700.5 \pm 89.7^{\mathrm{b}}$ & $415.9 \pm 55.3^{\mathrm{a}}$ & $321.4 \pm 52.2^{\mathrm{a}}$ & $445.0 \pm 66.7^{\mathrm{a}}$ & 0.04 & - & - \\
\hline NEFA, near AI $(\mathrm{mEq} / \mathrm{L})$ & $151.2 \pm 22.0$ & $132.3 \pm 13.9$ & $149.3 \pm 21.9$ & $147.2 \pm 14.2$ & 0.89 & - & - \\
\hline $\mathrm{DMI}^{2}(\mathrm{~kg} / \mathrm{d})$ & $22.7 \pm 0.3^{\mathrm{ab}}$ & $23.5 \pm 0.3^{\mathrm{b}}$ & $22.3 \pm 0.3^{\mathrm{ab}}$ & $20.7 \pm 0.3^{\mathrm{b}}$ & 0.10 & $<0.001$ & 0.22 \\
\hline $\mathrm{ECM}^{2}(\mathrm{~kg} / \mathrm{d})$ & $45.2 \pm 0.8^{\mathrm{a}}$ & $44.1 \pm 0.9^{\mathrm{a}}$ & $37.5 \pm 0.8^{\mathrm{b}}$ & $36.3 \pm 0.8^{\mathrm{b}}$ & 0.04 & $<0.001$ & 0.98 \\
\hline ECM, primiparous ${ }^{2}(\mathrm{~kg} / \mathrm{d})$ & $33.2 \pm 0.9^{\mathrm{ab}}$ & $35.4 \pm 0.8^{\mathrm{a}}$ & $31.6 \pm 0.6^{\mathrm{ab}}$ & $29.3 \pm 0.7^{\mathrm{b}}$ & 0.14 & $<0.001$ & 0.39 \\
\hline ECM, multiparous ${ }^{2}(\mathrm{~kg} / \mathrm{d})$ & $48.9 \pm 0.8^{\mathrm{B}}$ & $49.3 \pm 1.0^{\mathrm{B}}$ & $42.7 \pm 1.1^{\mathrm{A}}$ & $43.3 \pm 0.7^{\mathrm{A}}$ & 0.13 & $<0.001$ & 0.98 \\
\hline $\begin{array}{l}\text { Mean } \mathrm{P}^{3} \text { concentration at follicular } \\
\text { ablation }(\mathrm{ng} / \mathrm{mL})\end{array}$ & $2.24 \pm 0.23$ & $2.78 \pm 0.45$ & $2.82 \pm 0.26$ & $3.19 \pm 0.37$ & 0.52 & - & - \\
\hline $\begin{array}{l}\text { Cows with P4 concentration }<0.5 \mathrm{ng} / \mathrm{mL} \\
\text { at follicular ablation }(\%)\end{array}$ & $5.9(1 / 17)$ & $6.3(1 / 16)$ & $5.9(1 / 17)$ & $12.5(2 / 16)$ & 0.91 & - & - \\
\hline
\end{tabular}

${ }^{\mathrm{a}-\mathrm{d}}$ Values within a row with different superscript lowercase letters differ at $P<0.05$.

${ }^{\mathrm{A}, \mathrm{B}}$ Values within a row with different superscript capital letters differ at $P<0.15$.

${ }^{1}$ Fourth quartile $=$ most BW $(\mathrm{BW}+)$ loss.

${ }^{2}$ Average from calving until embryo collection.

${ }^{3} \mathrm{P} 4=$ progesterone. 
panel A). Cows in Q2 had no significant change in BW from first to sixth week postpartum, with increased $\mathrm{BW}$ from the sixth week postpartum until the end of the study period (Figure 4; panel A). In contrast to cows in Q1 and Q2, cows in Q3 lost BW from the first to the sixth week postpartum and gained weight from this time onwards (Figure 4; panel A). Interestingly, BW decreased drastically for Q4 cows from the first to the third week postpartum and remained constant from the third to the sixth week postpartum. A slight recovery in BW was observed from the sixth to the eighth week and remained constant until the end of the study period (Figure 4, panel A). Thus, from first to third week postpartum, Q1 cows gained, on average, $2.46 \%$ of BW, whereas Q2, Q3, and Q4 cows lost, on average, $0.96,2.96$, and $7.49 \%$ of $\mathrm{BW}$, respectively (Table $5)$. Percentage BW change did not differ $(P=0.84)$ between primiparous and multiparous cows (Table 6 ).

Nonesterified FA concentrations tended to differ $(P$ $=0.11$ ) among quartiles and were greater for $\mathrm{Q} 4$ cows and least for the other quartiles (Table 5). In addition, NEFA concentrations were greatest near calving and least at the end of the study period $(P<0.001)$. An interaction $(P=0.002)$ between quartiles and week is shown in Figure 4 (panel B). Cows in Q1, Q2, and Q4 had greater NEFA concentrations at calving or during the first week postpartum and decreased thereafter, whereas NEFA concentrations increased from calving to the third week postpartum in Q3 cows. Concentrations of NEFA did not differ among quartiles during the last $3 \mathrm{wk}$ of the study period. Overall, multiparous cows had greater $(P=0.02)$ NEFA concentrations compared with primiparous cows (Table 6).

As expected, DMI increased $(P<0.001)$ from the first week postpartum until the end of the study period for all quartiles (Figure 4, panel C). Overall, DMI tended to differ among quartiles $(P=0.10)$ and was greater for Q3 cows and lowest for $\mathrm{Q} 1$ cows $(P<0.05$; Table 5), whereas it was intermediate for Q2 and Q4 cows (Table 5; Figure 4, panel C). In addition, primiparous cows had lesser DMI compared with multiparous cows (19.4 vs. $24.2 \mathrm{~kg} / \mathrm{d} ; P<0.001$; Table 6 ).

Energy-corrected milk yield differed $(P=0.04)$ among quartiles and was greatest for Q3 and Q4 cows and least for Q1 and Q2 cows (44.1 and 45.2 vs. 36.3 and 37.5, respectively; Table 5). These effects may have been related to more primiparous cows in Q1 and Q2 than Q3 and Q4, as production of ECM was lowest ( $P$ $<0.001)$ for primiparous cows compared with multiparous cows (32.03 vs. $48.48 \mathrm{~kg}$, respectively; Table 6). In addition, ECM yield was lowest in the second week postpartum and increased until the fifth week $(P<$ 0.001; Figure 4, panel D).

\section{Embryo Characteristics}

No effect of parity on any of the embryo characteristics was detected (Table 6). Superovulatory response, total structures recovered, and recovery rate did not differ $(P>0.15)$ among quartiles (Table 7$)$. Similarly, total unfertilized structures (not shown), total fertilized structures, and percentage fertilization did not differ $(P$ $>0.15)$ among quartiles. Total degenerated embryos were greatest for Q4 cows, lowest for Q1 and Q2, and intermediate for Q3 (Table 7). The percentage degenerated embryos was similar among Q1, Q2, and Q3 cows and was greatest for Q4 cows (Table 7). Similarly, the percentage fertilized structures that were classified as degenerated embryos was greatest for Q4 and least for Q1, Q2, and Q3 $(P=0.04)$. Conversely, the percentage fertilized structures that were classified as quality 1 and $2(P=0.05)$ or quality 1,2 , and $3(P=0.04)$ were lower for Q4 than for the other quartiles (Table 7).

\section{DISCUSSION}

The relationship between BCS or other measures of energy balance and reproductive efficiency in lactating dairy cows has been the subject of many previous studies. A novel contribution of the present study is that a large number of cows were evaluated during a systematic reproductive management protocol (Double Ovsynch), which we expected to synchronize and induce cyclicity in the majority of cows before G1 of the breeding Ovsynch protocol. Our results indicate that this was successful because $93.1 \%$ (experiment 1) or $92.4 \%$ (experiment 3) of cows had increased $\mathrm{P} 4$ concentrations at G1 of the Ovsynch protocol. Thus, this strategy facilitated an understanding of the effects of energy balance on fertility, without the confounding effects of lack of cyclicity. Results from experiment 1 supported our first hypothesis because cows with low $(\leq 2.50)$ BCS near AI had decreased P/AI at first AI compared with cows with high $(\geq 2.75)$ BCS. The most striking relationship, however, was observed in experiment 2 in which improvements in BCS during the early postpartum period were associated with dramatically increased $\mathrm{P} / \mathrm{AI}$ to first AI. Overall, these results were consistent with our second hypothesis; however, a remarkable but unexplained difference between farms regarding the effect of BCS change on P/AI constrain our enthusiasm about the general applicability of this concept until this study is replicated on more farms. Finally, our results from cows superovulated at first AI provide extremely important and unique evidence on an important reproductive target of NEB. It seems clear that greater BW loss during the early postpartum period does not 


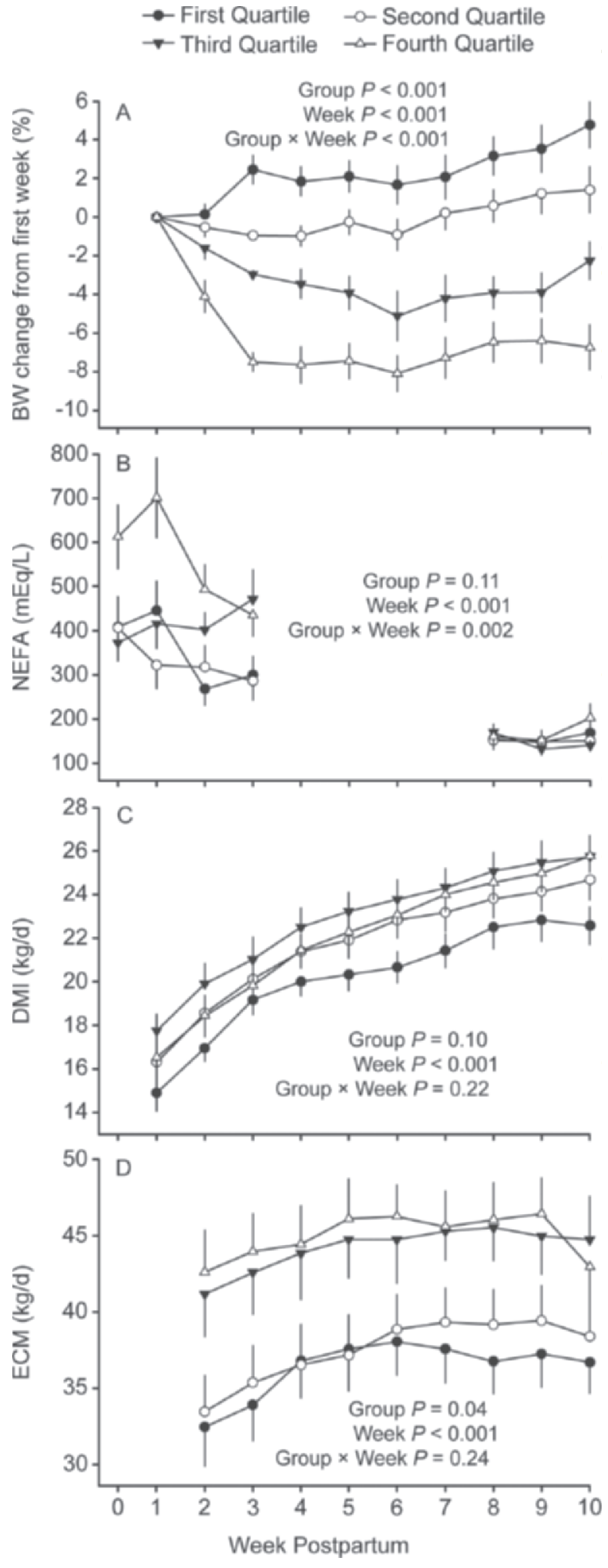

Figure 4. Percentage BW change from first week postpartum (panel A), NEFA concentrations during the first 3 wk postpartum and during the synchronization period (panel B), DMI (panel C), and ECM yield (panel D). Cows were ranked according to percentage BW change from the first to third week postpartum and divided into quartiles. Values are means \pm SEM. affect fertilization of oocytes but is associated with an increase in the percentage of degenerated embryos by 7 $\mathrm{d}$ after breeding, thus providing important evidence for a carryover effect of NEB on embryo development 6 to 7 wk later [Britt (1992) hypothesis].

Previous studies have shown that as BCS near AI increased, the proportion of cows with $\mathrm{P} 4$ concentrations less than $1 \mathrm{ng} / \mathrm{mL}$ decreased (Gümen et al., 2003; Lopez et al., 2004; Santos et al., 2009). Based on an analysis using 5,818 records from 13 studies of 8 dairy herds in the United States (Bamber et al., 2009), the rate of anovulation in lactating Holstein cows averaged $23 \%$ at 50 to 65 DIM, with a range among herds of 7.3 to $41.7 \%$. A similar proportion of anovular cows $(\sim 24 \%)$ has been reported in other studies (Lopez et al., 2004; Santos et al., 2009; Valenza et al., 2012; Garverick et al., 2013). Compared with a Presynch-Ovsynch protocol, a Double-Ovsynch protocol dramatically decreases the proportion of cows initiating the Ovsynch-56 protocol in a low-P4 environment (Souza et al., 2008; Herlihy et al., 2012; Ayres et al., 2013). This is important for interpreting the studies herein because the objective of experiment 1 was to examine the effects of BCS without the confounding effects of anovulation, as it is well described that cows with low $\mathrm{P} 4$ concentrations at the beginning of the Ovsynch protocol have decreased $\mathrm{P} /$ AI compared with cows with high $\mathrm{P} 4$ concentrations (Silva et al., 2007; Denicol et al., 2012; Giordano et al., 2012a,b, 2013). Furthermore, when pregnancy is established in anovular cows, these cows are more likely to undergo pregnancy loss compared with cyclic cows (Santos et al., 2004b, 2009; Sterry et al., 2006). In our study using Double Ovsynch for all breedings, a decrease of $8.8 \%$ in $\mathrm{P} / \mathrm{AI}$ occurred in cows with low BCS compared with high BCS (40.4 vs. $49.2 \% ; P=0.03$ ), which calculates to a relative decrease in $\mathrm{P} / \mathrm{AI}$ of $17.9 \%$ (8.8/49.2). Our observed effects of BCS are somewhat less dramatic compared with calculated relative reductions in $\mathrm{P} / \mathrm{AI}$ in other studies that compared fertility in cows with lower versus higher BCS: $33.1 \%$ (Ribeiro et al., 2011), 38.6\% (Ribeiro et al., 2012), 15.2\% (Santos et al., 2009), 25.3\% (Escalante et al., 2012), 45.7\% (Moreira et al., 2000), and 41.4\% (Souza et al., 2008). When only cows with increased $\mathrm{P} 4$ concentrations were analyzed in experiment 1, a tendency existed for lower fertility in low-BCS cows at both first $(P=0.10)$ and second pregnancy diagnosis $(P=0.06)$ with a similar relative reduction in $\mathrm{P} / \mathrm{AI}$ ( $16.7 \%$ at first and $20.2 \%$ at second pregnancy diagnosis) as observed with all cows included. Thus, our results support the idea that lower BCS near first AI is associated with decreased fertility and that other mechanisms, in addition to reduced cyclicity, perturb the fertility process in cows with low BCS. 
Table 6. Effect of parity on percentage BW change, NEFA concentrations, ECM, DMI, and embryo quality (values presented as mean $\pm \mathrm{SEM}$ )

\begin{tabular}{|c|c|c|c|}
\hline Item & $\begin{array}{l}\text { Primiparous } \\
(\mathrm{n}=26)\end{array}$ & $\begin{array}{l}\text { Multiparous } \\
(\mathrm{n}=40)\end{array}$ & $P$-value \\
\hline Initial BW (kg) & $530.1 \pm 8.3$ & $659.6 \pm 11.5$ & 0.18 \\
\hline BW change from first to third week (\%) & $-1.63 \pm 0.70$ & $-2.73 \pm 0.68$ & 0.36 \\
\hline BW change $e^{1}(\%)$ & $-1.07 \pm 0.33$ & $-2.73 \pm 0.27$ & 0.84 \\
\hline $\operatorname{NEFA}^{1}(\mathrm{mEq} / \mathrm{L})$ & $248.3 \pm 14.5$ & $338.7 \pm 15.2$ & 0.02 \\
\hline $\mathrm{DMI}^{1}(\mathrm{~kg} / \mathrm{d})$ & $19.4 \pm 0.2$ & $24.2 \pm 0.2$ & $<0.001$ \\
\hline $\operatorname{ECM}^{1}(\mathrm{~kg} / \mathrm{d})$ & $32.0 \pm 0.4$ & $46.5 \pm 0.5$ & $<0.001$ \\
\hline $\mathrm{P} 4^{2}$ concentration $(\mathrm{ng} / \mathrm{mL})$ at follicular ablation & $3.23 \pm 0.24$ & $2.44 \pm 0.22$ & 0.06 \\
\hline \multicolumn{4}{|l|}{ Embryo characteristics } \\
\hline Degenerated embryos (no.) & $0.84 \pm 0.2$ & $1.8 \pm 0.4$ & 0.68 \\
\hline Quality 1,2 , and 3 (no.) & $4.4 \pm 0.8$ & $5.3 \pm 0.9$ & 0.64 \\
\hline Fertilized (\%) & $79.7 \pm 5.5$ & $76.1 \pm 4.5$ & 0.64 \\
\hline Degenerated $(\%)$ & $15.8 \pm 4.6$ & $19.8 \pm 4.5$ & 0.99 \\
\hline Quality 1,2 , and 3 of fertilized (\%) & $80.1 \pm 5.2$ & $69.4 \pm 6.2$ & 0.55 \\
\hline
\end{tabular}

${ }^{1}$ Average from calving until embryo collection.

${ }^{2} \mathrm{P} 4=$ progesterone.

A commonly accepted idea regarding postpartum energy balance in dairy cows is that all or almost all cows lose BCS or weight during the postpartum period and that cows only differ in the degree to which they lose BCS or weight. The incidence of cows with low BCS $(\leq 2.5)$ in experiment 1 of this study $(23.6 \% ; 260 / 1103)$ was similar to a larger study $(25.8 \% ; 1,472 / 5,697)$ of lactating cows (Bamber et al., 2009). However, we were surprised at the relatively small degree of loss of BCS or BW observed in experiments 2 and 3. Only $41.8 \%$ $(789 / 1,887)$ of cows lost BCS during the first $21 \mathrm{~d}$ postpartum and this was similar for the 2 farms (experiment 2 ). Further, the observation that only $7.3 \%$ of cows lost 0.5 or more BCS $(139 / 1,887)$ during the first $21 \mathrm{~d}$ after calving seems somewhat at variance with previous re- ports of BCS losses of 1 or more units during the early postpartum period (López-Gatius et al., 2003; Gümen et al., 2005; Santos et al., 2009). Even more surprising was the observation that $33.5 \%(358 / 1,070)$ of cows on farm 2 gained BCS during the first $21 \mathrm{~d}$ after calving and that almost $60 \%$ of cows on either farm maintained or gained BCS during this early postpartum period. Similarly, in experiment 3, Q1 cows gained about 2.5\% of BW from the first to third week after calving, Q2 cows maintained BCS, Q3 cows lost approximately $4 \%$ of BW by 6 wk postpartum ( $\sim 25$ BCS), and only Q4 lost approximately $7.5 \%$ of BW in the early postpartum period, equivalent to about 0.5 BCS unit. Scientific studies reporting relatively low losses and even gains in $\mathrm{BCS}$ and BW during the early postpartum period are

Table 7. Embryo characteristics of lactating Holstein cows based on BW change from first to third week postpartum (values presented as mean $\pm \mathrm{SEM}$

\begin{tabular}{|c|c|c|c|c|c|}
\hline \multirow[b]{2}{*}{ Item } & \multicolumn{4}{|c|}{ Quartile group ${ }^{1}$} & \multirow[b]{2}{*}{$P$-value } \\
\hline & $\begin{array}{l}\text { Lost BW+: } \\
\text { fourth quartile }\end{array}$ & $\begin{array}{l}\text { Lost BW: } \\
\text { third quartile }\end{array}$ & $\begin{array}{l}\text { Maintained BW: } \\
\text { second quartile }\end{array}$ & $\begin{array}{l}\text { Gained BW: } \\
\text { first quartile }\end{array}$ & \\
\hline Corpora lutea (no.) & $18.4 \pm 2.6$ & $18.4 \pm 1.7$ & $19.0 \pm 1.7$ & $16.0 \pm 2.0$ & 0.67 \\
\hline Total ova/embryos (no.) & $9.6 \pm 2.5$ & $10.6 \pm 1.7$ & $6.4 \pm 1.2$ & $7.4 \pm 1.4$ & 0.31 \\
\hline Fertilized structures (no.) & $7.6 \pm 2.1$ & $7.3 \pm 1.1$ & $4.8 \pm 1.1$ & $5.8 \pm 1.4$ & 0.43 \\
\hline Degenerated embryos (no.) & $2.7 \pm 0.7^{\mathrm{a}}$ & $1.7 \pm 0.7^{\mathrm{ab}}$ & $0.7 \pm 0.2^{\mathrm{b}}$ & $0.6 \pm 0.2^{\mathrm{b}}$ & 0.02 \\
\hline Quality 1 and 2 (no.) & $4.2 \pm 1.4$ & $5.3 \pm 0.9$ & $3.9 \pm 1.1$ & $4.9 \pm 1.4$ & 0.47 \\
\hline Quality 1,2 , and 3 (no.) & $4.9 \pm 1.6$ & $5.6 \pm 0.8$ & $4.1 \pm 1.1$ & $5.3 \pm 1.4$ & 0.49 \\
\hline Fertilized $(\%)$ & $76.9 \pm 7.1$ & $77.0 \pm 6.6$ & $77.6 \pm 7.6$ & $78.4 \pm 7.1$ & 0.99 \\
\hline Degenerated (\%) & $35.2 \pm 8.5^{\mathrm{a}}$ & $12.6 \pm 4.6^{\mathrm{b}}$ & $14.5 \pm 6.3^{\mathrm{b}}$ & $9.6 \pm 3.7^{\mathrm{b}}$ & 0.02 \\
\hline Quality 1 and $2(\%)$ & $38.0 \pm 8.7^{\mathrm{b}, \mathrm{B}}$ & $61.3 \pm 8.2^{\mathrm{ab}, \mathrm{A}}$ & $60.6 \pm 9.4^{\mathrm{ab}, \mathrm{A}}$ & $63.4 \pm 8.6^{\mathrm{a}, \mathrm{A}}$ & 0.14 \\
\hline Quality 1,2 , and $3(\%)$ & $41.7 \pm 8.8^{\mathrm{b}, \mathrm{B}}$ & $64.4 \pm 8.2^{\mathrm{ab}, \mathrm{A}}$ & $63.1 \pm 9.3^{\mathrm{ab}, \mathrm{A}}$ & $68.9 \pm 8.7^{\mathrm{a}, \mathrm{A}}$ & 0.13 \\
\hline Degenerated of fertilized (\%) & $46.9 \pm 9.6^{\mathrm{a}, \mathrm{A}}$ & $17.4 \pm 6.4^{\mathrm{b}, \mathrm{B}}$ & $24.8 \pm 9.3^{\mathrm{ab}, \mathrm{A}}$ & $16.2 \pm 7.0^{\mathrm{b}, \mathrm{B}}$ & 0.04 \\
\hline Quality 1 and 2 of fertilized (\%) & $48.4 \pm 9.5^{\mathrm{b}}$ & $78.3 \pm 6.6^{\mathrm{a}}$ & $72.6 \pm 9.5^{\mathrm{a}}$ & $77.7 \pm 7.4^{\mathrm{a}}$ & 0.05 \\
\hline Quality 1,2 , and 3 of fertilized (\%) & $53.2 \pm 9.6^{\mathrm{b}, \mathrm{B}}$ & $82.6 \pm 6.4^{\mathrm{a}, \mathrm{A}}$ & $75.2 \pm 9.3^{\mathrm{a}, \mathrm{AB}}$ & $83.8 \pm 7.0^{\mathrm{a}, \mathrm{A}}$ & 0.04 \\
\hline Recovery rate $(\%)$ & $45.6 \pm 7.4$ & $55.1 \pm 6.9$ & $35.4 \pm 6.7$ & $45.3 \pm 5.8$ & 0.25 \\
\hline
\end{tabular}

$\overline{\mathrm{a}, \mathrm{b}}$ Values within a row with different superscript lowercase letters differ at $P<0.05$.

${ }^{\mathrm{A}, \mathrm{B}}$ Values within a row with different superscript capital letters differ at $P<0.15$.

${ }^{1}$ Fourth quartile $=$ most BW $(\mathrm{BW}+)$ loss. 
not common in the literature (Britt, 1992; Gümen et al., 2005). This difference from our study may be due to differences in nutritional and health management during the transition period. Cows on the dairies in experiment 2 and 3 were fed higher-fiber, controlledenergy diets during the transition period, a fairly recent nutritional management strategy. These diets have been linked to lower loss of BCS during the first $6 \mathrm{wk}$ postpartum and better reproduction (Cardoso et al., 2013). Thus, our results and future studies may need to be considered within the context of how innovations in nutritional management of the transition period may affect comparison of recent results to results of previous studies, particularly in relation to BCS loss.

The most fascinating results in our study were the dramatic differences in $\mathrm{P} / \mathrm{AI}$ that were observed in cows due to BCS change during the early postpartum period. In contrast, a meta-analysis of 11 studies described in 10 scientific manuscripts ( $\mathrm{n}=7,733$ cows $)$ published before 2003 found no effect of change in BCS during the early postpartum period on $\mathrm{P} / \mathrm{AI}$ at first service (López-Gatius et al., 2003). In support of our results, a more recent study (Santos et al., 2009) reported that cows losing more BCS between calving and first AI were less likely to conceive at first AI and were more likely to experience pregnancy loss. In our study, cows with an increase in BCS had increased P/AI (at 70-d pregnancy diagnosis) by an astonishing $42.3 \%$ (78.3$36.0 \%$ ) compared with cows maintaining BCS and $55.5 \%$ (78.3-22.8\%) compared with cows losing BCS during the first 3 wk postpartum. This calculates to a relative improvement in fertility of $118 \%$ (42.3/36.0) for cows gaining compared with maintaining BCS and over a 240\% (55.5/22.8) improvement for cows gaining compared with losing BCS. This difference could also be observed in the dramatic improvement in time to pregnancy in the cows that gained BCS during the early postpartum period. The BCS at parturition was slightly greater for cows that subsequently lost BCS (2.93) compared with cows that maintained (2.89) or gained (2.85) BCS; however, this minor difference seems unlikely to explain the extraordinary fertility differences. In addition, the parity differences between BCS categories seem unlikely to explain the results, as primiparous and multiparous had similar differences in fertility based on change in BCS. Overall, our results agree with the Britt (1992) hypothesis, which postulates that NEB during the early postpartum period is associated with decreased $\mathrm{P} / \mathrm{AI}$ at first AI. Our results, however, do not allow identification of the mechanism(s) whereby cows gaining BCS during the early postpartum period have such exceptional fertility at first AI after Double Ovsynch and TAI. Nevertheless, the large number of cows in all BCS categories (n
$=1,887$ overall), the magnitude of the response, and the strong statistical significance $(P<0.001)$ make it unlikely, in our minds, to be due to random chance despite the dramatic differences between the 2 farms.

In spite of our confidence in the overall scientific validity of the results of experiment 2 , we are puzzled by the overt differences between farm 1 and 2 . On farm 2 , a greater proportion of cows $(\sim 33 \%)$ gained BCS and these cows had exceedingly high P/AI compared with cows that lost or maintained BCS. However, only $8.0 \%$ of cows gained BCS on farm 1 and these cows had similar P/AI compared with cows that maintained or lost BCS. In addition, a similar proportion of cows on both farms lost BCS during the first 3 wk after calving (42.5 vs. $41.3 \%$ ); however, a reduction in fertility occurred in cows that lost BCS on farm 2 (only $15.4 \%$ P/AI; 68/442) but not on farm 1 (32.3\%; 112/347). These results support our hypothesis that cows losing BCS would have decreased P/AI; however, we did not expect such differences between farms. Moreover, these 2 farms were sister operations under the same ownership located within $8 \mathrm{~km}$ of each other. Differences in milk production existed between the 2 farms. Farm 2 had the lowest milk production, the greatest fertility, and the most dramatic effect of early postpartum BCS change on fertility. It is currently unclear if this difference in milk production or some other unknown difference provides an explanation for the puzzling differences that were observed between farms. Interestingly, 3 recent studies reported differing results when NEFA concentrations during the transition period were compared with fertility of dairy cows. One study (Ospina et al., 2010b) reported that cows with greater NEFA concentrations during the transition period had fewer pregnancies during the first $70 \mathrm{~d}$ of the breeding season. Similarly, Garverick et al. (2013) reported an association between $\mathrm{P} / \mathrm{AI}$ at first service and NEFA concentrations at $3 \mathrm{~d}$ after calving. In contrast, Chapinal et al. (2012a) reported that NEFA concentrations were not associated with fertility. The study that reported the most dramatic effect of postpartum NEFA concentration on fertility (Garverick et al., 2013) used Ovsynch in cycling cows and in anovular cows, used Ovsynch with a CIDR to synchronize ovulation for first AI. It seems possible that use of the Double-Ovsynch protocol in our study could have augmented the effect of early-postpartum energy balance on fertility, at least on farm 2. Obviously future studies are needed to evaluate the effects of variation in postpartum energy balance between cows and between herds in relation to fertility differences in response to Double Ovsynch or other reproductive management strategies. In addition, we were unable to detect an effect of BCS at calving on $\mathrm{P} / \mathrm{AI}$ at first $\mathrm{AI}(P=0.80)$ or time to pregnancy $(P$ 
$=0.16$; data not shown). In contrast to our results, a previous study reported an effect of BCS at dry-off on time to pregnancy (Machado et al., 2010).

Our final study allowed us to evaluate the association between postpartum BW loss and early events in the reproductive process, specifically fertilization and embryonic development until $7 \mathrm{~d}$ after breeding. We used a modified Double-Ovsynch protocol for superstimulation, because other studies in superovulated cows reported that low $\mathrm{P} 4$ concentrations during the superstimulation protocol were associated with an increased proportion of both unfertilized ova and degenerate embryos (Rivera et al., 2011). To the best of our knowledge, this was the first time that an in vivo study reported a negative association between BW loss early postpartum and decreased embryo quality in lactating dairy cows. Results from in vitro studies have reported decreased fertilization rates (Leroy et al., 2005) after addition of NEFA concentrations to the in vitro maturation medium. Our results do not suggest that acute differences in NEFA concentrations underlie our results because all quartiles had low and similar NEFA concentrations near the time of superovulation and AI. In addition, we found no evidence that increases in BW loss had any effect on fertilization rate, based on correlation coefficients (Table 4) or quartile analysis (Table 7).

In contrast to the lack of effect of postpartum BW loss on fertilization, a detectable effect of BW change existed during the first $3 \mathrm{wk}$ or first $9 \mathrm{wk}$ on percentage of embryos that became degenerated during the first week of development or, conversely, the percentage of high-quality embryos (1 and 2; or 1, 2, and 3) on d 7 . The most dramatic effect was observed in cows that were losing BW, which had almost 50\% degenerated embryos compared with about $80 \%$ good-quality embryos in the other 3 quartiles. Thus, some of the effects of NEB during the early postpartum period appear to involve a reduction in early embryo development. A decrease in early in vivo embryo quality occurred when naturally ovulating lactating cows were compared with nonlactating dry cows (Sartori et al., 2002); when single-ovulating lactating cows were induced to ovulate older, possibly persistent, rather than younger, dominant follicles (Cerri et al., 2009); and when lactating cows were superovulated in the presence of low P4 concentrations compared with high $\mathrm{P} 4$ concentrations (Rivera et al., 2011). Previous results have generally been attributed to alterations in the oocyte, possibly due to overstimulation of the preovulatory follicle by excessive LH pulses. In our studies, no effect of milk production on results in experiments 2 or 3 was detected and no parity effects were observed in experiment 3 , making these unlikely to be the primary causative factors. In addition, no detectable differences existed between quartiles in ovulatory response, size of follicles, or P4 concentrations during superstimulation. Consistent with our results in superovulated cows, Santos et al. (2013) performed a retrospective analysis of data from several studies in which embryos were collected from single ovulating animals and reported that cows that were diagnosed with ketosis during the early postpartum period had similar percentages of oocytes that were fertilized but poorer embryo quality compared with healthy herd mates (Santos et al., 2013). The mechanism(s) producing this effect are not yet defined but could involve active uptake of NEFA into the oocyte during the early postpartum period, leading to impairments in subsequent early embryo development, as reported during in vitro studies (Leroy et al., 2005; Aardema et al., 2011); impaired accumulation of mRNA, proteins, or other factors in the maturing oocyte (Lonergan et al., 2003; Wu et al., 2010; Yang et al., 2012); or even disorders of the uterine environment, as severe NEB can increase uterine expression of markers of inflammation and tissue remodeling (Wathes et al., 2007). Regardless of mechanism, cows with the greatest BW loss during early postpartum appear to have impairments in embryo development during the first week after first AI.

Multiple practical implications can be drawn from our results. First, nutritional consultants and farmers should focus on reducing or eliminating NEB and loss of BCS and BW during the early postpartum period, as well as ensuring that cows have BCS of more than 2.5 at first AI to optimize fertility. Our studies suggest that optimizing transition management can improve fertility even in herds that implement programs that induce cyclicity such as a Double-Ovsynch protocol for first AI. Future studies are needed to definitively test this idea in studies that manipulate transition management protocols. From a genetic perspective, selection of cows with reduced BW change during the early postpartum period could not only lead to healthier dairy cows but also cows with improved fertility. This idea is consistent with studies linking early postpartum clinical and subclinical diseases with subsequent fertility. Finally, major farm management implications exist if it is possible to replicate and understand why one-third of cows gained BCS during the first $3 \mathrm{wk}$ after calving on farm 2 in experiment 2, and why these cows exhibited such phenomenal fertility. The observation that farm 2 had lower milk production than farm 1 is an obvious possible explanation for the betweenfarm differences; however, other possible management differences cannot be ruled out at this time. Future mechanistic and practical studies are needed to fully understand and use the intriguing results discovered during this investigation. 


\section{ACKNOWLEDGMENTS}

The authors thank the 7 participating dairies and their staff for their unselfish contribution of time, cows, and facilities during this project. Technical support was also generously provided by Sandy Bertics from the department of Dairy Science (University of Wisconsin-Madison) and Daniel Luchini (Adisseo USA Inc., Alpharetta, GA). Accelerated Genetics Inc. (Baraboo, WI) prepared and donated the semen used in experiment 3. This research was supported by the USDA Agriculture and Food Research Initiative (AFRI) Competitive Grant no. 2010-85122-20612, Adisseo USA Inc., Balchem (New Hampton, NY), and Hatch projects WIS01171 to P. M. Fricke and WIS01240 to M. C. Wiltbank.

\section{REFERENCES}

Aardema, H., P. L. A. M. Vos, F. Lolicato, B. A. J. Roelen, H. M. Knijn, A. B. Vaandrager, J. B. Helms, and B. M. Gadella. 2011. Oleic acid prevents detrimental effects of saturated fatty acids on bovine oocyte developmental competence. Biol. Reprod. 85:62-69.

Ayres, H., R. M. Ferreira, A. P. Cunha, R. R. Araujo, and M. C Wiltbank. 2013. Double-Ovsynch in high-producing dairy cows: Effects on progesterone concentrations and ovulation to $\mathrm{GnRH}$ treatments. Theriogenology 79:159-164.

Bamber, R. L., G. E. Shook, M. C. Wiltbank, J. E. P. Santos, and P. M. Fricke. 2009. Genetic parameters for anovulation and pregnancy loss in dairy cattle. J. Dairy Sci. 92:5739-5753.

Bell, A. W. 1995. Regulation of organic nutrient metabolism during transition from late pregnancy to early lactation. J. Anim. Sci. 73:2804-2819.

Bergfelt, D. R., K. C. Lightfoot, and G. P. Adams. 1994. Ovarian synchronization following ultrasound-guided transvaginal follicle ablation in heifer. Theriogenology 42:895-907.

Britt, J. 1992. Impacts of early postpartum metabolism on follicular development and fertility. Pages 29-43 in Proc. Annu. Conv. Am. Assoc. Bovine Pract. Am. Assoc. Bovine Pract., Auburn, AL.

Butler, W. R. 2003. Energy balance relationships with follicular development, ovulation and fertility in postpartum dairy cows. Livest. Prod. Sci. 83:211-218.

Butler, W. R. 2005. Inhibition of ovulation in the postpartum cow and the lactating sow. Livest. Prod. Sci. 98:5-12.

Canfield, R. W., and W. R. Butler. 1990. Energy balance and pulsatile LH secretion in early postpartum dairy cattle. Domest. Anim. Endocrinol. 7:323-330.

Cardoso, F. C., S. J. LeBlanc, M. R. Murphy, and J. K. Drackley. 2013. Prepartum nutritional strategy affects reproductive performance in dairy cows. J. Dairy Sci. 96:5859-5871.

Cerri, R. L. A., H. M. Rutigliano, R. C. Chebel, and J. E. P. Santos, 2009. Period of dominance of the ovulatory follicle influences embryo quality in lactating dairy cows. Reproduction 137:813-823.

Chapinal, N., M. E. Carson, S. J. LeBlanc, K. E. Leslie, S. Godden, M. Capel, J. E. P. Santos, M. W. Overton, and T. F. Duffield. 2012a. The association of serum metabolites in the transition period with milk production and early-lactation reproductive performance. J. Dairy Sci. 95:1301-1309.

Chapinal, N., S. J. LeBlanc, M. E. Carson, K. E. Leslie, S. Godden, M. Capel, J. E. P. Santos, M. W. Overton, and T. F. Duffield. 2012b. Herd-level association of serum metabolites in the transition period with disease, milk production, and early lactation reproductive performance. J. Dairy Sci. 95:5676-5682.

Denicol, A. C., G. Lopes Jr., L. G. D. Mendonça, F. A. Rivera, F. Guagnini, R. V. Perez, J. R. Lima, R. G. S. Bruno, J. E. P. Santos, and R. C. Chebel. 2012. Low progesterone concentration during the development of the first follicular wave reduces pregnancy per insemination of lactating dairy cows. J. Dairy Sci. 95:1794-1806.

Edmonson, A. J., I. J. Lean, L. D. Weaver, T. Farver, and G. Webster 1989. A body condition scoring chart for Holstein dairy cows. J. Dairy Sci. 72:68-78.

Escalante, R. C., S. E. Poock, D. J. Mathew, W. R. Martin, E. M. Newsom, S. A. Hamilton, K. G. Pohler, and M. C. Lucy. 2012 Short communication: Presynchronization for timed artificial insemination in grazing dairy cows by using progesterone for 14 days with or without prostaglandin $\mathrm{F}_{2 \alpha}$ at the time of progesterone withdrawal. J. Dairy Sci. 95:5102-5108.

Ferguson, J. D. 1996. Diet, production and reproduction in dairy cows. Anim. Feed Sci. Technol. 59:173-184.

Garverick, H. A., M. N. Harris, R. Vogel-Bluel, J. D. Sampson, J Bader, W. R. Lamberson, J. N. Spain, M. C. Lucy, and R. S. Youngquist. 2013. Concentrations of nonesterified fatty acids and glucose in blood of periparturient dairy cows are indicative of pregnancy success at first insemination. J. Dairy Sci. 96:181-188.

Giordano, J. O., M. C. Wiltbank, P. M. Fricke, S. Bas, R. Pawlisch, J. N. Guenther, and A. B. Nascimento. 2013. Effect of increasing GnRH and $\mathrm{PGF}_{2 \alpha}$ dose during Double-Ovsynch on ovulatory response, luteal regression, and fertility of lactating dairy cows. Theriogenology 80:773-783.

Giordano, J. O., M. C. Wiltbank, J. N. Guenther, M. S. Ares, G Lopes Jr., M. M. Herlihy, and P. M. Fricke. 2012a. Effect of presynchronization with human chorionic gonadotropin or gonadotropin-releasing hormone 7 days before resynchronization of ovulation on fertility in lactating dairy cows. J. Dairy Sci. 95:5612-5625.

Giordano, J. O., M. C. Wiltbank, J. N. Guenther, R. Pawlisch, S. Bas, A. P. Cunha, and P. M. Fricke. 2012b. Increased fertility in lactating dairy cows resynchronized with Double-Ovsynch compared with Ovsynch initiated $32 \mathrm{~d}$ after timed artificial insemination. J. Dairy Sci. 95:639-653.

Grummer, R. R. 1995. Impact of changes in organic nutrient metabolism on feeding the transition dairy cow. J. Anim. Sci. 73:28202833

Grummer, R. R. 2008. Nutritional and management strategies for the prevention of fatty liver in dairy cattle. Vet. J. 176:10-20.

Grummer, R. R., and R. R. Rastani. 2003. Review: When should lactating dairy cows reach positive energy balance? Prof. Anim. Sci. 19:197-203.

Gümen, A., J. N. Guenther, and M. C. Wiltbank. 2003. Follicular size and response to Ovsynch versus detection of estrus in anovular and ovular lactating dairy cows. J. Dairy Sci. 86:3184-3194.

Gümen, A., R. R. Rastani, R. R. Grummer, and M. C. Wiltbank. 2005. Reduced dry periods and varying prepartum diets alter postpartum ovulation and reproductive measures. J. Dairy Sci. $88: 2401-2411$

Herdt, T. H. 2000. Ruminant adaptation to negative energy balance. Influences on the etiology of ketosis and fatty liver. Vet. Clin. North Am. Food Anim. Pract. 16:215-230,v.

Herlihy, M. M., J. O. Giordano, A. H. Souza, H. Ayres, R. M. Ferreira, A. Keskin, A. B. Nascimento, J. N. Guenther, J. M. Gaska, S. J. Kacuba, M. A. Crowe, S. T. Butler, and M. C. Wiltbank. 2012. Presynchronization with Double-Ovsynch improves fertility at first postpartum artificial insemination in lactating dairy cows. J. Dairy Sci. 95:7003-7014.

Leroy, J. L. M. R., T. Vanholder, B. Mateusen, A. Christophe, G. Opsomer, A. de Kruif, G. Genicot, and A. Van Soom. 2005. Nonesterified fatty acids in follicular fluid of dairy cows and their effect on developmental capacity of bovine oocytes in vitro. Reproduction 130:485-495.

Lonergan, P., D. Rizos, A. Gutiérrez-Adán, P. M. Moreira, B. Pintado, J. de la Fuente, and M. P. Boland. 2003. Temporal divergence in the pattern of messenger RNA expression in bovine embryos cultured from the zygote to blastocyst stage in vitro or in vivo. Biol. Reprod. 69:1424-1431.

Lopes, G., Jr., J. O. Giordano, A. Valenza, M. M. Herlihy, J. N. Guenther, M. C. Wiltbank, and P. M. Fricke. 2013. Effect of timing of initiation of resynchronization and presynchronization with gonad- 
otropin-releasing hormone on fertility of resynchronized inseminations in lactating dairy cows. J. Dairy Sci. 96:3788-3798.

Lopez, H., D. Z. Caraviello, L. D. Satter, P. M. Fricke, and M. C. Wiltbank. 2005. Relationship between level of milk production and multiple ovulations in lactating dairy cows. J. Dairy Sci. 88:2783-2793.

Lopez, H., L. D. Satter, and M. C. Wiltbank. 2004. Relationship between level of milk production and estrous behavior of lactating dairy cows. Anim. Reprod. Sci. 81:209-223.

López-Gatius, F., J. Yániz, and D. Madriles-Helm. 2003. Effects of body condition score and score change on the reproductive performance of dairy cows: A meta-analysis. Theriogenology 59:801812

Machado, V. S., L. S. Caixeta, J. A. A. McArt, and R. C. Bicalho. 2010. The effect of claw horn disruption lesions and body condition score at dry-off on survivability, reproductive performance, and milk production in the subsequent lactation. J. Dairy Sci. 93:4071-4078.

Moreira, F., C. Risco, M. F. A. Pires, J. D. Ambrose, M. Drost, M. DeLorenzo, and W. W. Thatcher. 2000. Effect of body condition on reproductive efficiency of lactating dairy cows receiving a timed insemination. Theriogenology 53:1305-1319.

NRC. 2001. Nutrient Requirements of Dairy Cattle. 7th rev. ed. National Academies Press, Washington, DC.

Ospina, P. A., D. V. Nydam, T. Stokol, and T. R. Overton. 2010a. Association between the proportion of sampled transition cows with increased nonesterified fatty acids and $\beta$-hydroxybutyrate and disease incidence, pregnancy rate, and milk production at the herd level. J. Dairy Sci. 93:3595-3601.

Ospina, P. A., D. V. Nydam, T. Stokol, and T. R. Overton. 2010b. Associations of elevated nonesterified fatty acids and $\beta$-hydroxybutyrate concentrations with early lactation reproductive performance and milk production in transition dairy cattle in the northeastern United States. J. Dairy Sci. 93:1596-1603.

Ribeiro, E. S., R. L. A. Cerri, R. S. Bisinotto, F. S. Lima, F. T. Silvestre, L. F. Greco, W. W. Thatcher, and J. E. P. Santos. 2011. Reproductive performance of grazing dairy cows following presynchronization and resynchronization protocols. J. Dairy Sci. 94:4984-4996.

Ribeiro, E. S., A. P. A. Monteiro, F. S. Lima, H. Ayres, R. S. Bisinotto, M. Favoreto, L. F. Greco, R. S. Marsola, W. W. Thatcher, and J. E. P. Santos. 2012. Effects of presynchronization and length of proestrus on fertility of grazing dairy cows subjected to a 5-day timed artificial insemination protocol. J. Dairy Sci. 95:2513-2522.

Rivera, F. A., L. G. D. Mendonça, G. Lopes, J. E. P. Santos, R. V. Perez, M. Amstalden, A. Correa-Calderón, and R. C. Chebel. 2011. Reduced progesterone concentration during growth of the first follicular wave affects embryo quality but has no effect on embryo survival post transfer in lactating dairy cows. Reproduction 141:333-342.

Santos, J. E. P., R. S. Bisinotto, E. S. Ribeiro, N. Martinez, and F. S. Lima. 2013. Role of animal health on reproduction of dairy cows. Pages $32-38$ in Proc. Dairy Cattle Reprod. Counc. Conf. Dairy Cattle Reproduction Council, Champaign, IL.

Santos, J. E. P., S. O. Juchem, R. L. A. Cerri, K. N. Galvão, R. C. Chebel, W. W. Thatcher, C. S. Dei, and C. R. Bilby. 2004a. Effect of bST and reproductive management on reproductive performance of Holstein dairy cows. J. Dairy Sci. 87:868-881.

Santos, J. E. P., H. M. Rutigliano, and M. F. S. Filho. 2009. Risk factors for resumption of postpartum estrous cycles and embryonic survival in lactating dairy cows. Anim. Reprod. Sci. 110:207-221.
Santos, J. E. P., W. W. Thatcher, R. C. Chebel, R. L. A. Cerri, and K. N. Galvão. 2004b. The effect of embryonic death rates in cattle on the efficacy of estrus synchronization programs. Anim. Reprod. Sci. 82-83:513-535.

Sartori, R., R. Sartor-Bergfelt, S. A. Mertens, J. N. Guenther, J. J. Parrish, and M. C. Wiltbank. 2002. Fertilization and early embryonic development in heifers and lactating cows in summer and lactating and dry cows in winter. J. Dairy Sci. 85:2803-2812.

Sartori, R., C. A. Suárez-Fernández, R. L. Monson, J. N. Guenther, G. J. M. Rosa, and M. C. Wiltbank. 2003. Improvement in recovery of embryos/ova using a shallow uterine horn flushing technique in superovulated Holstein heifers. Theriogenology 60:1319-1330.

Silva, E., R. A. Sterry, D. Kolb, M. C. Wiltbank, and P. M. Fricke. 2007. Effect of pretreatment with prostaglandin $\mathrm{F}_{2 \alpha}$ before resynchronization of ovulation on fertility of lactating dairy cows. J. Dairy Sci. 90:5509-5517.

Souza, A. H., H. Ayres, R. M. Ferreira, and M. C. Wiltbank. 2008. A new presynchronization system (Double-Ovsynch) increases fertility at first postpartum timed AI in lactating dairy cows. Theriogenology 70:208-215.

Sterry, R. A., M. L. Welle, and P. M. Fricke. 2006. Treatment with gonadotropin-releasing hormone after first timed artificial insemination improves fertility in noncycling lactating dairy cows. J. Dairy Sci. 89:4237-4245.

Stringfellow, D. A., and M. D. Givens. 2010. Manual of the International Embryo Transfer Society: A Procedural Guide and General Information for the Use of Embryo Transfer Technology Emphasizing Sanitary Precautions. 4th ed. International Embryo Transfer Society, Champaign, Ill.

Valenza, A., J. O. Giordano, G. Lopes Jr., L. Vincenti, M. C. Amundson, and P. M. Fricke. 2012. Assessment of an accelerometer system for detection of estrus and treatment with gonadotropin-releasing hormone at the time of insemination in lactating dairy cows. J. Dairy Sci. 95:7115-7127.

Wathes, D. C., M. Fenwick, Z. Cheng, N. Bourne, S. Llewellyn, D. G. Morris, D. Kenny, J. Murphy, and R. Fitzpatrick. 2007. Influence of negative energy balance on cyclicity and fertility in the high producing dairy cow. Theriogenology 68(Suppl. 1):S232-S241.

Weber, C., C. Hametner, A. Tuchscherer, B. Losand, E. Kanitz, W. Otten, S. P. Singh, R. M. Bruckmaier, F. Becker, W. Kanitz, and H. M. Hammon. 2013. Variation in fat mobilization during early lactation differently affects feed intake, body condition, and lipid and glucose metabolism in high-yielding dairy cows. J. Dairy Sci. 96:165-180.

Wu, L. L.-Y., K. R. Dunning, X. Yang, D. L. Russell, M. Lane, R. J. Norman, and R. L. Robker. 2010. High-fat diet causes lipotoxicity responses in cumulus-oocyte complexes and decreased fertilization rates. Endocrinology 151:5438-5445.

Yang, X., L. L. Wu, L. R. Chura, X. Liang, M. Lane, R. J. Norman, and R. L. Robker. 2012. Exposure to lipid-rich follicular fluid is associated with endoplasmic reticulum stress and impaired oocyte maturation in cumulus-oocyte complexes. Fertil. Steril. 97:14381443.

Zurek, E., G. R. Foxcroft, and J. J. Kennelly. 1995. Metabolic status and interval to first ovulation in postpartum dairy cows. J. Dairy Sci. 78:1909-1920. 